\title{
Anti-seizure activity of African medicinal plants: The identification of bioactive alkaloids from the stem bark of Rauvolfia caffra using an in vivo zebrafish model
} \author{
Gill M. Enslin ${ }^{\text {a,* }}$

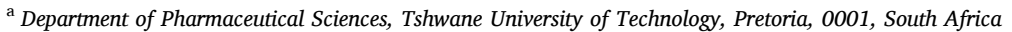 \\ ${ }^{\mathrm{b}}$ SAMRC Herbal Drugs Research Unit, Tshwane University of Technology, Pretoria, 0001, South Africa \\ ${ }^{\mathrm{c}}$ Luxembourg Centre for Systems Biomedicine (LCSB), University of Luxembourg, Esch-sur- Alzette, 4362, Luxembourg \\ ${ }^{\mathrm{d}}$ Department of Preclinical Sciences and Pathology, Norwegian University of Life Sciences, Oslo, Norway \\ e Institute for Orphan Drug Discovery, Bremer Innovations- und Technologiezentrum, Bremen, Germany \\ ${ }^{\mathrm{f}}$ School of Chemistry and Physics, Pietermaritzburg Campus, University of KwaZulu-Natal, Scottsville, 3209, South Africa
}

Talent Chipiti $^{\mathrm{a}}$, Alvaro M. Viljoen ${ }^{\mathrm{a}, \mathrm{b}}$, Maria L. Cordero-Maldonado ${ }^{\mathrm{c}}$, Clinton G.L. Veale ${ }^{\mathrm{f}}$, Fanie R. Van Heerden ${ }^{\mathrm{f}}$, Maxleene Sandasi ${ }^{\mathrm{a}}$, Weiyang Chen ${ }^{\mathrm{a}}$, Alexander D. Crawford ${ }^{\mathrm{c}, \mathrm{d}, \mathrm{e}}$,

\section{A R T I C L E I N F O}

\section{Keywords:}

Zebrafish

Rauvolfia caffra

Epilepsy

Pleiocarpamine

Rauverine $\mathrm{H}$

\begin{abstract}
A B S T R A C T
Ethnopharmacological relevance: Epilepsy is one of the major chronic diseases that does not have a cure to date. Adverse drug reactions have been reported from the use of available anti-epileptic drugs (AEDs) which are also effective in only two-thirds of the patients. Accordingly, the identification of scaffolds with promising antiseizure activity remains an important first step towards the development of new anti-epileptic therapies, with improved efficacy and reduced adverse effects. Herbal medicines are widely used in developing countries, including in the treatment of epilepsy but with little scientific evidence to validate this use. In the search for new epilepsy treatment options, the zebrafish has emerged as a chemoconvulsant-based model for epilepsy, mainly because of the many advantages that zebrafish larvae offer making them highly suitable for high-throughput drug screening.

Aim of the study: In this study, 20 medicinal plants traditionally used in South Africa to treat epilepsy were screened for anti-epileptic activity using a zebrafish larvae model.

Materials and methods: Toxicity triaging was conducted on 120 crude extracts, 44 fractions and three isolated compounds to determine the maximum tolerated concentration (MTC) of each extract, fraction or compound. MTC values were used to guide the concentration range selection in bioactivity studies. The effectiveness of crude extracts, fractions and isolated compounds from Rauvolfia caffra Sond. in suppression of pentylenetetrazole (PTZ) induced seizure-like behaviour in a 6-dpf zebrafish larvae model was measured using the PTZ assay.

Results: Following a preliminary toxicity triage and bioactivity screen of crude extracts from 20 African plants used traditionally for the treatment and management of epilepsy, the methanolic extract of Rauvolfia caffra Sond. was identified as the most promising at suppressing PTZ induced seizure-like behaviour in a zebrafish larvae model. Subsequent bioactivity-guided fractionation and spectroscopic structural elucidation resulted in the isolation and identification of two tryptoline derivatives; a previously unreported alkaloid to which we assigned the trivial name rauverine $\mathrm{H}$ (1) and the known alkaloid pleiocarpamine (2). Pleiocarpamine was found to reduce PTZ-induced seizures in a dose-dependent manner.

Conclusions: Accordingly, pleiocarpamine represents a promising scaffold for the development of new antiseizure therapeutic compounds. Furthermore, the results of this study provide preliminary evidence to support the traditional use of Rauvolfia caffra Sond. in the treatment and management of epilepsy. These findings warrant further studies on the anti-epileptic potential of Rauvolfia caffra Sond. using other models.
\end{abstract}

\footnotetext{
Abbreviations: CNS, central nervous system; DBE, double bond equivalent; MTC, maximum tolerated concentration; PTZ, pentylenetetrazole.

* Corresponding author.

E-mail address: enslingm@tut.ac.za (G.M. Enslin).
} 


\section{Introduction}

Epilepsy, a debilitating central nervous system (CNS) disorder, has a disproportionately high prevalence amongst people living in low- and middle-income regions. Epilepsy currently afflicts approximately $1 \%$ of the global population with almost $80 \%$ of these found in developing countries (Fricke-Galindo et al., 2018; Owolabi et al., 2020; Hacke et al., 2021). The economic implications of epilepsy are significant, this disorder is ranked the fourth largest cause of global disease burden (Zuberi and Symonds, 2015), indicating the extent of the burden that epilepsy places on healthcare systems globally.

Despite a variety of current treatment options, epilepsy remains uncontrolled in roughly one-third of patients, as well as being associated with numerous adverse drug reactions including amnesia, joint or muscle pain, tremors, and depression (Fricke-Galindo et al., 2018; Cunliffe, 2016; Kowski, 2016; Schmidt, 2009). These adverse reactions have a detrimental effect on the individual's quality-of-life and discourage treatment adherence, with up to $25 \%$ of patients discontinuing treatment, with a concomitant burden on the economy due to inadequate control of the disease (Singh and Trevick, 2016).

Accordingly, the identification of scaffolds with promising antiseizure activity remains an important first step toward the development of new anti-epileptic therapies, with improved efficacy and reduced adverse effects.

Although plants and plant-derived products have been utilized by mankind throughout history as a source of medicine, many of the most widely used medicinal plants have not yet been investigated comprehensively to ascertain their bioactivity and possible toxicity (Schachter, 2009). Traditional remedies for the treatment of epilepsy are still commonly used in many regions of the world including Africa (Auditeau et al., 2019), and therefore offer a potential treasure trove for the identification of new hit anti-seizure compounds. The combination of modern-day techniques, models and traditional knowledge are potentially valuable in the rapid detection and isolation of bioactive components from crude plant extracts (CRBA, 2010; Galstyan et al., 2021). The most widely used models for epilepsy research are rodents, rabbits, primates and guinea pigs. However, in the last two decades the zebrafish (Danio rerio), has emerged as a valuable species for epilepsy studies because of by the advantages offered by this species over other models
(CRBA, 2010; Galstyan et al., 2021). Given their close physiological and genetic homology to humans, in addition to their broad range of disease associated phenotypes, zebrafish (Danio rerio) models are proving increasingly useful disease surrogates in early drug discovery (MacRae and Peterson., 2015). Furthermore, the ease with which zebrafish can be bred, monitored and manipulated, make them eminently suitable for high-throughput drug screening (Wiley et al., 2017) and bioactivity-guided natural product discovery (Crawford et al., 2008). Zebrafish larvae, exposed to chemoconvulsants such as the $\mathrm{GABA}_{\mathrm{A}}$ antagonist pentylenetetrazole (PTZ), experience acute seizure-like behaviour which mimics the changes in brain electrophysiology observed in rodent seizure models. Furthermore, marked behavioural changes, observed in humans with epilepsy, such as convulsive seizures, are replicated in phenotypic changes in zebrafish behaviour, including quantifiable changes in locomotor activity. The ictal and interictal-like epileptiform discharge recordings from the larval optic tectum and the upregulation of c-fos expression that is observed in CNS structures of zebrafish larvae are evidence of the suitability of this model. Marked behavioural changes, often accompanied by varying degrees of loss of consciousness and severe locomotor convulsions, are observed in humans during an epileptic seizure. Accordingly, zebrafish assays represent important validated models of epilepsy, which can be exploited to for the microscale in vivo bioactivity-guided isolation of new natural product compounds with anti-seizure activity potential (Cunliffe, 2015; Challal et al., 2014; Tiraboschi et al., 2020). The objective of this study was to screen South African medicinal plants used traditionally to manage epilepsy for bioactivity using a zebrafish (Danio rerio) larvae model in combination with chromatographic and spectroscopic techniques for the isolation and structural elucidation of potentially bioactive compounds. A survey of 20 African medicinal plants, selected based on their reported traditional use (Table 1) was conducted. Toxicity triaging, followed by biological screening, identified the crude methanolic extract of Rauvolfia caffra Sond. as the most promising source of non-toxic inhibitors of zebrafish hyper-locomotion. Subsequent bioactivity-guided fractionation resulted in the identification of two tryptoline derivatives, the previously unreported rauverine $\mathrm{H}$, and the known compound pleiocarpamine. Validation bioassays revealed that while rauverine $\mathrm{H}$ was ineffective at disrupting PTZ-induced seizure-like behaviour, pleiocarpamine reduced PTZ-induced seizure-like

Table 1

Plant species and plant parts used in the study for potential anti-epileptic activity.

\begin{tabular}{|c|c|c|c|c|}
\hline Botanical name & Plant family & Plant part(s) used & Reported traditional use & Reference \\
\hline Afzelia africana $\mathrm{Sm}$. & Fabaceae & Roots & Convulsions & Kinsou et al. (2019) \\
\hline Aframomum melegueta $\mathrm{K}$. Schum. & Zingiberaceae & Whole stem & Epilepsy & Umukoro \& Ashorobi (2005) \\
\hline Annona senegalensis Pers. & Annonaceae & Stem bark & Epilepsy & Okoye et al. (2013) \\
\hline Anchomanes difformis (Bl.) Engl. & Araceae & Calyx & Epilepsy & Bello et al. (2019) \\
\hline Bacopa monnieri (L.) Pennell & Plantaginaceae & Aerial parts, stem & Epilepsy & Mathew et al. (2010) \\
\hline Bersama lucens (Hochst.) Szyszyl. & Melianthaceae & Leaves & Epilepsy & Bosch (2008) \\
\hline Costus afer Ker Gawl. & Costaceae & Whole plant & Epilepsy & $\begin{array}{l}\text { Personal communication at Faraday Herbal } \\
\text { Market }\end{array}$ \\
\hline $\begin{array}{l}\text { Dioscorea dregeana (Kunth) T. Durand \& } \\
\text { Schinz. }\end{array}$ & Dioscoreaceae & Stem bark and roots & $\begin{array}{l}\text { CNS ailments including } \\
\text { epilepsy }\end{array}$ & Mothogoane et al. (2013) \\
\hline Elephantorrhiza elephantina (Burch.) Skeels. & Fabaceae & $\begin{array}{l}\text { Aerial parts and } \\
\text { roots }\end{array}$ & CNS ailments & $\begin{array}{l}\text { Personal communication at Faraday Herbal } \\
\text { Market }\end{array}$ \\
\hline Garcinia kola Hecke.l. & Clusiaceae & Fruits & Epilepsy & Owoeye et al. (2015) \\
\hline Hibiscus sabdariffa L. & Malvaceae & Seeds & Epilepsy & Kulkarni et al. (2011) \\
\hline Landolphia owariensis P. Beauv. & Apocynaceae & Leaves & Convulsions and epilepsy & Burkill (1985) \\
\hline Leonotis leonurus (L.) R.Br. & Lamiaceae & Tubers & Epilepsy and seizures & Bienvenu et al. (2002) \\
\hline Mondia whitei (Hook.f.) Skeels & Apocynaceae & Stem bark & Epilepsy & Lamidi \& Bourobou (2010) \\
\hline Myrothamnus flabellifolius Welw. & Myrothamnaceae & Tubers & Epileptic seizures & $\begin{array}{l}\text { Personal communication at Faraday Herbal } \\
\text { Market }\end{array}$ \\
\hline Rauvolfia caffra Sond. & Apocynaceae & Seeds & Epilepsy & Mollel et al. (2007)a,b \\
\hline Rauvolfia vomitoria Afzel. & Apocynaceae & Aerial parts & Epilepsy & Olatokunboh et al. (2009) \\
\hline Synaptolepis kirkii Oliv. & Thymelaeaceae & Roots & CNS ailments & $\begin{array}{l}\text { Personal communication at Faraday Herbal } \\
\text { Market }\end{array}$ \\
\hline Withania somnifera (L.) Dunal. & Solanaceae & Roots & Epilepsy & Kulkarni et al. (1993) \\
\hline Xylopia aethiopica (Dunal) A. & Annonaceae & Stem bark & Seizures & $\begin{array}{l}\text { Personal communication at Faraday Herbal } \\
\text { Market }\end{array}$ \\
\hline
\end{tabular}


Table 2

Primer combinations used for PCR amplification and Sanger sequencing of the plant species selected for this study.

\begin{tabular}{|c|c|c|c|}
\hline Region/Primer Name & Direction & Primer Sequence & Reference \\
\hline \multicolumn{4}{|l|}{$r b c L a$} \\
\hline rbcLa-F & Forward & ATGTCACCACAAACAGACTAAAGC & Levin et al. (2003) \\
\hline rbcLa-R & Reverse & GTAAAATCAAGTCCACCRCG & Kress et al. (2009) \\
\hline \multicolumn{4}{|l|}{ matK } \\
\hline matK-KIM_3F & Forward & CGTACAGTACTTTTGTGTTTACGAG & Hollingsworth et al. (2009) \\
\hline matK-KIM_1R & Reverse & AATATCCAAATACCAAATCC & Hollingsworth et al. (2009) \\
\hline
\end{tabular}

behaviour in an apparently dose-dependent manner, thus representing an important hit compound for the development of new therapies for epilepsy.

\section{Materials and methods}

The order of experimental workflow from plant species selection, MTC determination and PTZ assay for potential anticonvulsant activity on extracts and isolates, through to active compound identification in Rauvolfia caffra is presented schematically in the supplementary information (Figure S1).

\subsection{Chemicals and reagents}

In this study, all chemicals, reagents and solvents used for extraction were of analytical reagent grade (AR), all liquid chromatographic solvents and buffers were of HPLC grade. The purity levels of the antiepileptic drugs used as controls were valproic acid, 98\% and diazepam, $\geq 98 \%$.

\subsection{Selection of plant species}

Various electronic databases, such as Scopus and Science Direct, and the African Herbal Pharmacopeia (Brendler et al., 2010) were consulted to identify plants used in traditional medicine for the treatment and management of epilepsy and related conditions. The following terms were used in the literature search: epilepsy + seizure + fits + African medicinal plants. A total of 20 African medicinal plants were selected for further study, based on their reported traditional use, but lack of supporting evidence in literature to confirm this use. The plant material (Table 1), which included aerial parts (flowers, buds and twigs, leaves, stem, stem bark) and roots were sourced from Faraday market Johannesburg, South Africa and Parceval Pharmaceuticals (Pty) Ltd, Wellington, South Africa. The material was identified by A Viljoen (botanist) but for authentication of the species, the plant material was subjected to DNA bar coding. Voucher specimens and retention samples are retained in the Department of Pharmaceutical Sciences at the Tshwane University of Technology, Pretoria, South Africa.

\subsection{Preparation of plant extracts}

Plant material was dried in an oven at $50{ }^{\circ} \mathrm{C}$, then ground in a Retsch BB 400 mill (Retsch Laboratories, South Africa). Six solvents of different polarities (distilled water, methanol, acetone, dichloromethane, ethyl acetate and hexane) were used to prepare extracts using $5 \mathrm{~g}$ of each of the relevant powdered plant parts and $50 \mathrm{~mL}$ of solvent. The extraction process was facilitated by sonicating each sample for $30 \mathrm{~min}$ (Ultrasound Sonicator, United Scientific, South Africa), each new solvent extraction was carried out using a new sample of plant material. After filtering the extracts through Whatman ${ }^{\circledR}$ filter paper (No. 1), the filtrates were concentrated under reduced pressure using a rotary evaporator (Buchi II Rotavapor ${ }^{\mathrm{TM}}$ (Labotec, South Africa)) at $40{ }^{\circ} \mathrm{C}$. Nonpolar organic filtrates were concentrated using a GeneVac ${ }^{\mathrm{TM}}$ centrifugal evaporator (SP Scientific, South Africa), and aqueous filtrates concentrated by freeze drying in an AdVantage ${ }^{\mathrm{TM}} 2.0$ benchtop freeze dryer (SP
Scientific, South Africa). The dried extracts were weighed and transferred to airtight Eppendorf $®$ microtubes (Labotec, South Africa) and stored at $4{ }^{\circ} \mathrm{C}$. All solvents and mobile phase constituents, hexane, dichloromethane, ethyl acetate, acetone, methanol, acetonitrile and ammonia were of analytical reagent grade.

\subsection{DNA barcoding}

A verification study was performed to determine the identity of 20 samples to species level, where possible, using DNA barcoding, at the African Centre for DNA Barcoding (ACDB), Department of Botany and Plant Biotechnology, University of Johannesburg, South Africa.

Total genomic DNA was extracted from plant material using Nucleospin ${ }^{\circledR}$ PLANT II Tissue Kits (Macherey-Nagel, Bethlehem, PA, USA) as per the manufacturer's specifications. Polymerase chain reaction (PCR) amplification for the rbcLa and matK regions, the two officially accepted barcoding loci in this taxonomic tool, was performed in $25 \mu \mathrm{L}$ reactions in a Gene Amp ${ }^{\circledR}$ PCR System 9700 (Waltham, Massachusetts, USA) thermocycler. The primer pairs used for amplification are listed in Table 2.

Each of the PCR reactions contained 12,5 $\mu \mathrm{L}$ of Applied Biosystems's DreamTaq polymerase, $1,0 \mu \mathrm{L}$ of bovine serum albumin, $0,3 \mu \mathrm{L}$ of both forward and reverse primers, $0,5 \mu \mathrm{L} \mathrm{MgCl}_{2}$ and 9,6 $\mu \mathrm{L}$ biology grade water. PCR products were visualized on $1,5 \%$ agarose gel. A negative control was included in all experiments to ensure that no exogenous DNA was introduced into the PCR reactions. PCR products were purified using ExoSAP-IT (Thermofisher Scientific) and incubated at $37^{\circ} \mathrm{C}$ for 15 min, followed by $15 \mathrm{~min}$ at $80^{\circ} \mathrm{C}$ to remove any unincorporated primers and deoxynucleoside triphosphates.

Cycle sequencing reactions were executed using the BigDye ${ }^{\circledR}$ Terminator V3.1 kit (Thermofisher Scientific). Cycle sequencing products were precipitated in ethanol and sodium acetate to remove any excess dye terminator before being sequenced on an ABI $3130 \times 1$ genetic analyser. Sequence trace files (ABI) were imported into the bioinformatics software Geneious $\mathrm{R}$ (v10.2.6, Biomatters Ltd.). Bidirectional sequences were trimmed and assembled into contigs using the de novo assemble function, the Geneious assembler and the highest sensitivity/slow setting. Sequences were trimmed for quality (error probability limit 0.05 and trim from both $3^{\prime}$ and $5^{\prime}$ ends) and to auto remove primer sites. Sequences below $70 \%$ high quality (HQ) or less than 500 base pairs were considered failures and not analysed. Assembled contigs had an average HQ score of $>90 \%$ for rbcLa and an average HQ score $>50 \%$ for matK. All passing sequences (low-high) were compared to the National Centre for Biotechnology Information's (NCBI) Genbank database through Geneious, using the "BLAST" (basic local alignment search tool) function with the default parameters. The highest percentage match was reported, however, only matches of $98 \%$ or greater were considered accurate.

\subsection{Zebrafish larvae bioassays}

\subsubsection{Ethics statement}

In this project, all work using zebrafish was performed at the Zebrafish Core Facility in the Luxembourg Centre for Systems Biomedicine. This Facility is registered as an authorized breeder, supplier and 


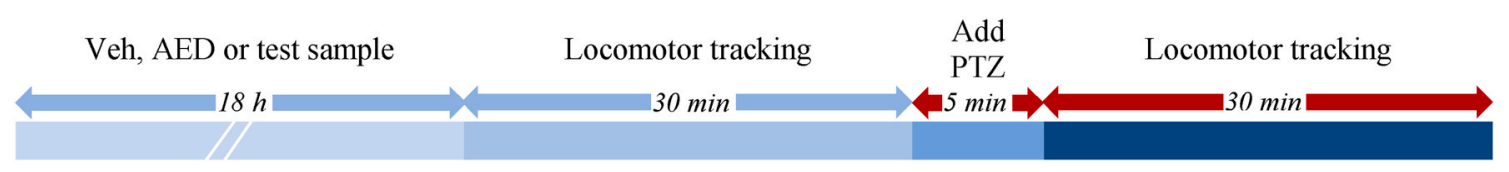

Fig. 1. Timeline schematic of treatment parameters, order in which they were applied and the key time-points for each experimental protocol. AED $=$ anti-epileptic drug, Test sample $=$ the extract, fraction and compounds under study, PTZ = pentylenetetrazole, Veh $=$ vehicle.

user of zebrafish with Grand-Ducal decree of January 20, 2016. All practices involving zebrafish were performed in accordance with European laws, guidelines and policies for animal experimentation, housing and care (European Directive, 2010/63/EU on the protection of animals used for scientific purposes), and follows the principles of the Three R's - to replace, reduce and refine the use of animals used in scientific research. In addition, the experimental procedures performed in the present study were authorized with number LUPA 2019/87.

\subsubsection{Animal husbandry}

Adult zebrafish ((Danio rerio) aged $\geq 3$ months) stocks of the $\mathrm{AB}$ wild type strain were maintained at $28.5^{\circ} \mathrm{C}$, on a $14 / 10$-h light/dark cycle under standard aquaculture conditions (Westerfield, 2000). The male to female ratio was maintained at approximately 50:50, for breeding, the ratios ranged from $2: 1$ to $3: 2$, female to male respectively, in mating cages. Embryos were obtained by natural spawning and after collection and sorting, fertilized embryos were reared in $0.3 \mathrm{X}$ Danieau's medium

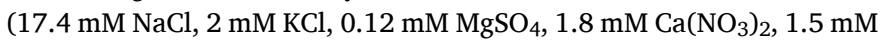
HEPES pH 7.6 and $1.2 \mu \mathrm{M}$ methylene blue) at $28^{\circ} \mathrm{C}\left( \pm 0.5^{\circ} \mathrm{C}\right)$. Medium exchange was carried out daily to ensure the viability of the larvae for the assays, until 6-dpf.

\subsubsection{Preparation of stock and test solutions}

Stock solutions of the required concentrations (ranging from $10 \mu \mathrm{g}$ / $\mathrm{mL}$ to $1000 \mu \mathrm{g} / \mathrm{mL}$ ) of the crude extracts, fractions and pure compounds were prepared using either 100\% DMSO (Sigma- Aldrich, St. Louis, MO, USA; AR grade) or ultrapure water (Milli-Q ${ }^{\circledR}$, Merck), depending on their solubility, and were stored at $-20{ }^{\circ} \mathrm{C}$ until needed. Valproic acid (VPA) (Sigma-Aldrich, Belgium) and diazepam (DZP) (Sigma-Aldrich, Belgium) were used as standard anti-epileptic drugs (AEDs). Stock solutions of valproic acid, $200 \mathrm{mM}$, were prepared in ultrapure water, and of diazepam, $10 \mathrm{mM}$, in 100\% DMSO. From these stock solutions, all corresponding test solutions were then freshly prepared on the day of the experiment in the vehicle (Veh, $0.3 X$ Danieau's medium with $1 \%$ DMSO). For the anticonvulsant bioassay, a stock solution of $40 \mathrm{mM} \mathrm{PTZ}$ (Sigma-Aldrich, Belgium) was freshly prepared prior each experiment in $0.3 X$ Danieau's medium.

\subsubsection{Toxicological evaluation and determination of maximum tolerated concentration (MTC)}

Prior to all in vivo assays, the maximum tolerated concentration (MTC) was determined for all crude extracts (Table S1, supplementary data), fractions and isolated compounds, in order to establish the range of safe concentrations for use in the PTZ bioassays. Guidelines described by Afrikanova et al. (2013), were followed, with slight modifications. Zebrafish larvae, 6-dpf (at this stage male to female ratio was unknown since it is difficult differentiate between the sexes at this early larval age), were incubated in 48-well microplates (five larvae per well) with either $500 \mu \mathrm{L}$ of Veh, $1 \mathrm{mM}$ VPA or $16 \mu \mathrm{M}$ diazepam as the AED positive control, or the test groups comprising plant extracts, fractions or isolated pure compounds at concentrations ranging from $10 \mu \mathrm{g} / \mathrm{mL}$ to 1000 $\mu \mathrm{g} / \mathrm{mL}$. Immediately after exposure each well was visually assessed under a stereo microscope (Olympus SXZ10, Belgium) for any signs of acute locomotor impairment and any abnormal larvae were removed. The plate was then covered with aluminium foil, to create an environment of complete darkness and incubated for $18 \mathrm{~h}$ at $28.5^{\circ} \mathrm{C}$. At the end of the incubation period the assessment of the larvae was repeated. The following were considered signs of acute locomotor impairment: hypoactivity, decreased or no touch/escape response upon a light touch of the tail with a fine needle, loss of posture, body deformation, exophthalmos, slow or absent heartbeat, and ultimately death. A larva was considered normal if it could travel a distance equivalent to twice its body length. A shorter distance travelled, or movement in the same place, was scored as a decreased or impaired touch response. No visible movement upon a touch stimulus was counted as a no response. The MTC was considered to be the maximum concentration of the test solution that did not cause death or toxicity in more than two out of five larvae in a well after the $18 \mathrm{~h}$ incubation period. All toxicity tests were conducted in triplicate and MTCs of extracts, fractions or pure compounds were considered acceptable for further testing and were evaluated for anticonvulsant activity using the PTZ assay.

\subsubsection{Evaluation of anticonvulsant activity: pentylenetetrazole (PTZ) assay}

The anticonvulsant activity assay was conducted using the method described by Afrikanova et al. (2013), with minor modifications. The locomotor activity of zebrafish larvae was tracked and recorded over two 30-min periods, using a specialized high-resolution video camera tracking system (DanioVision, ${ }^{\mathrm{TM}}$ Noldus, Wageningen, The Netherlands), after incubation in test and control solutions and again after exposure to the convulsant drug, PTZ (Fig. 1, Video clip, SV1 in supplementary data).

Six-dpf larvae were pre-incubated in 96-well microplates (one larva per well with $100 \mu \mathrm{L}$ of $1 \mathrm{mM}$ VPA or $16 \mu \mathrm{M}$ diazepam as the positive control, crude extracts, fractions or pure compounds (at a range of concentrations below or equal to MTC values) or Veh as the negative control, for $18 \mathrm{~h}$ at $28.5^{\circ} \mathrm{C}$ in complete darkness. Five larvae per extract/ fraction/compound were used per experiment for the initial screening, which was increased to ten for the subsequent concentration response studies of extracts with potential bioactivity. All experiments were conducted in triplicate. Following the $18 \mathrm{~h}$ pre-incubation, video tracking of locomotor activity was conducted for $30 \mathrm{~min}$ in the dark. After this period, video tracking was suspended, and $100 \mu \mathrm{L}$ of $40 \mathrm{mM}$ PTZ was added to each well, except in the negative control, resulting in an effective final concentration of $20 \mathrm{mM}$ PTZ per well. For the negative control $100 \mu \mathrm{L}$ of $0.3 X$ Danieau's medium $0.3 X(100 \mu \mathrm{L})$ was added to each corresponding well. After addition of PTZ, larvae were allowed to habituate for $5 \mathrm{~min}$ in the dark chamber of the automated tracking device. After this, video tracking was resumed for a further $30 \mathrm{~min}$. The total locomotor activity was then quantified (EthoVision ${ }^{\mathrm{TM}} \mathrm{XT}$, Noldus, Wageningen, The Netherlands) and total distance moved expressed in $\mathrm{mm}$.

\subsection{Chemical profiling, isolation and structural elucidation of bioactive compounds}

The chromatographic chemical profiling of extracts found to be potentially active in the PTZ bioassay, the subsequent fractionation, isolation and structural elucidation of the active compounds is described in this section.

\subsubsection{Preparative ultra-performance liquid chromatography mass spectrometry (UPLC-MS) analysis}

Fractionation of the crude plant extracts and isolation of bioactive compounds was performed on a Waters AutoPurification ${ }^{\mathrm{TM}}$ chromatographic system fitted with a Waters photodiode array (2998 PDA) 
detector, and mass spectrometer (Waters, Milford, MA, USA). The crude extracts were prepared for injection at a concentration of $50 \mathrm{mg} / \mathrm{mL}$ in methanol and filtered $\left(0.22 \mu \mathrm{m}\right.$; Millipore $\left.{ }^{\circledR}\right)$. Injection volumes ranged from 100 to $300 \mu \mathrm{L}$. The chromatographic conditions were optimised to achieve good separation of the sample constituents. Separation was achieved on an XBridge ${ }^{\mathrm{TM}}$ Preparative $\mathrm{C} 18$ column $(19 \times 250 \mathrm{~mm}$, i. d., $5 \mu \mathrm{m}$ particle size, Waters) maintained at $40{ }^{\circ} \mathrm{C}$. The mobile phase consisted of $0.1 \%$ ammonium hydroxide (Solvent A) and acetonitrile (Solvent B; ultra-gradient grade; Romil, Cambridge, England), at a flow rate of $20 \mathrm{~mL} / \mathrm{min}$. Gradient elution was applied as follows: Initial ratio $90 \%$ A:10\% B, maintained for $1 \mathrm{~min}$, changed to $55 \%$ A:45\% B over 4 min, changed to $15 \%$ A: $85 \%$ B within 7 min, to $5 \%$ A:95\% B within 0.5 $\mathrm{min}$ and returning to the initial ratio within $0.5 \mathrm{~min}$. The total run time was $13 \mathrm{~min}$.

The preparative HPLC system was interfaced with an Acquity ${ }^{\mathrm{TM}}$ QDaTM mass detector (Waters, Milford, MA, USA), positive ionization mode. The probe temperature was set at $600{ }^{\circ} \mathrm{C}$ and source temperature at $120^{\circ} \mathrm{C}$. The capillary and cone voltages were set to 800 and $10 \mathrm{~V}$, respectively. Data were collected between $\mathrm{m} / \mathrm{z} 100$ and 650 using MassLynx TM 4.1 (Waters, USA) software. Fractions were obtained by collecting 1-min aliquots of the eluent from the active crude extracts into test tubes arranged in collection trays. The target compounds were collected from various runs, and subsequently combined to obtain a sufficiently large volume of each fraction, and analysed by ultraperformance liquid chromatography-mass spectrometry (UPLC-MS).

\subsubsection{UPLC-MS analysis}

A Waters UPLC-MS system was used for analysis of all crude extracts, fractions and isolated compounds. The system was fitted with a Waters PDA detector (Milford, Massachusetts (MA), USA). A $1 \mu \mathrm{L}$ volume of each sample ( $1 \mathrm{mg} / \mathrm{mL}$ in methanol) was analysed. Separation was accomplished using an Acuity ${ }^{\mathrm{TM}}$ UPLC BEH C18 column $(150 \mathrm{~mm} \times 2.1$ $\mathrm{mm}$ i. d., $1.7 \mu \mathrm{m}$ particle size). The mobile phase consisted of $0.1 \%$ ammonium hydroxide (Solvent A, HPLC grade) and acetonitrile (Solvent B; ultra-gradient grade; Romil, Cambridge, England), at a flow rate of $0.3 \mathrm{~mL} / \mathrm{min}$. Gradient elution was applied as follows: Initial ratio $95 \%$ A:5\% B, changed to $80 \% \mathrm{~A}: 20 \%$ B over 3 min, changed to $50 \%$ A:50\% B within $7 \mathrm{~min}$, to $45 \% \mathrm{~A}: 55 \%$ B within $1 \mathrm{~min}$, to $5 \%$ A:95\% B within 2 $\mathrm{min}$, keeping for $1 \mathrm{~min}$ and returning to the initial ratio within $0.5 \mathrm{~min}$. The total run time was $16 \mathrm{~min}$.

The UPLC-MS system was interfaced with a Xevo ${ }^{\mathrm{TM}} \mathrm{G} 2$ Quadrupole Time-of-Flight mass spectrometer (qToF-MS) (Waters, USA). The mass spectrum was obtained in positive electrospray ionization mode, as this yielded better sensitivity. Nitrogen at a flow rate of $500 \mathrm{~L} / \mathrm{h}$ was used as the desolvation gas, with desolvation temperature set to $350{ }^{\circ} \mathrm{C}$. A source temperature of $100{ }^{\circ} \mathrm{C}$ was maintained. The capillary and sampling cone voltages were set to 3000 and $38 \mathrm{~V}$, respectively. Data were collected between $m / z 100$ and 1500 and processed by Masslynx ${ }^{\mathrm{TM}} 4.1$ chromatographic software.

\subsubsection{Nuclear magnetic resonance spectroscopy analysis}

Proton $\left({ }^{1} \mathrm{H}\right)(500 \mathrm{MHz})$ and carbon-13 $\left({ }^{13} \mathrm{C}\right) \mathrm{NMR}(125 \mathrm{MHz})$, correlation spectroscopy (COSY), heteronuclear single quantum coherence (HSQC) and heteronuclear multiple bond correlation (HMBC) spectra were recorded on a Bruker AvanceTM III 500 spectrometer. All proton and carbon chemical shifts are quoted relative to the relevant residual solvent signal (MeOD: ${ }^{1} \mathrm{H}, 3.31 \mathrm{ppm},{ }^{13} \mathrm{C}, 49.00 \mathrm{ppm}$ ). Coupling constants are reported in $\mathrm{Hz}$. All experiments were conducted at $30{ }^{\circ} \mathrm{C}$ unless specified otherwise.

\subsubsection{Data analysis}

Locomotor behaviour data were first normalized against the Veh + PTZ controls from the same tracking experiment, and the normalized data from replicate tracking runs were subsequently pooled. Antiepileptic drug plus pentylenetetrazole (AED + PTZ) treatment and Test (crude extracts, fractions and compounds) + PTZ groups were compared to Veh + PTZ groups using repeated measures (mixed model) ANOVA. Both electrographic parameters and the average total movement over the 30 min period were compared using Student's T-test oneway ANOVA, followed by Dunnett's multiple comparison test using Graph Pad 7 Prism $^{\mathrm{TM}}$ software (GraphPad Software, San Diego, USA). Differences with $\mathrm{P}<0.05$ were considered significant.

\section{Results and Discussion}

\subsection{Identification and verification of the identity of selected plant species}

Species identification was confirmed by the African Centre for DNA barcoding at the University of Johannesburg, South Africa. A total of 15 plants, where able to be identified to species level with a high confidence level. Three plants were identified to genus level and two plant species, Landolphia owiowariensis and Xylopia aethiopica, could not be identified due to lack of reference standards in the database. Where two possible species were indicated from the DNA library, the geographic distribution map for the species used as an aid to correct identification, as was the case for Rauvolfia verticillata/Rauvolfia caffra assigned as Rauvolfia caffra due geographical distribution matching. The majority of the plant species identity was assigned to species level, confirming that the vernacular names used by traditional healers and herbalists are accurate. This also underlines the value of complementary techniques such as DNA barcoding in correctly identifying medicinal plants, and where possible (as in this study) an independent, non-affiliated laboratory should be used.

The responsible development of governance compliant medicinal products mandates obtaining valid scientific evidence on the quality, efficacy and safety of medicinal plants. This includes ascertaining the toxicity profile prior to any bioactivity testing. In the current study the MTC values yielded valuable information on concentration determination for each sample of herbal extract that did not compromise the normal survival of the zebrafish larvae in bioassays (Gad, 2014).

This section provides details of the results obtained during toxicity studies performed on crude vehicle and the standard AEDs used in the study and the assessment of the effect of crude plant extracts on the locomotor activity of zebrafish larvae using the PTZ assay.

\subsubsection{Maximum tolerated concentrations (MTCs)}

Fifty of the 120 crude extracts tested (Table S1, supplementary data) proved toxic to the larvae at the lowest concentration, $10 \mu \mathrm{g} / \mathrm{mL}$. The MTCs of the remaining 70 extracts ranged from $10 \mu \mathrm{g} / \mathrm{mL}$ to nontoxic at the highest concentration tested, $1000 \mu \mathrm{g} / \mathrm{mL}$. The highest MTC values recorded were, for the majority of the plants, those from the aqueous extracts. It was also determined that as the polarity of the extraction solvent decreased, the MTC value of the extract decreased. Aqueous extracts were consequently found to be tolerated by larvae at higher concentrations than more non-polar extracts. The MTC values were determined for 18 out of a total of 20 crude extracts.

The Xylopia aethiopica and Bersama lucens aqueous extracts were toxic at all the concentrations tested; for these extracts more than three larvae out of five in a well died due to toxicity and in many cases all larvae died, indicative of the severity of the toxicity of the extracts.

The ethyl acetate extracts were found to be the most toxic, with 11 out of 20 extracts found to be toxic over the full concentration range tested. This observation can be explained by two potential contributing factors: first, it is well documented that the more toxic secondary metabolites are found in the non-polar extracts and second, while every effort was made to evaporate all solvent residue from extracts, some residue of the toxic ethyl acetate may have remained trapped in the extract matrix, with a concomitant toxic effect. Many studies in which the effects of various plant extracts have been studied, it has been reported that, most notably, that the water extracts are less toxic compared to the organic solvent extracts (Boukandou et al., 2015; Ferreira- Machado et al., 2004). It is feasible that the most toxic principles 
A
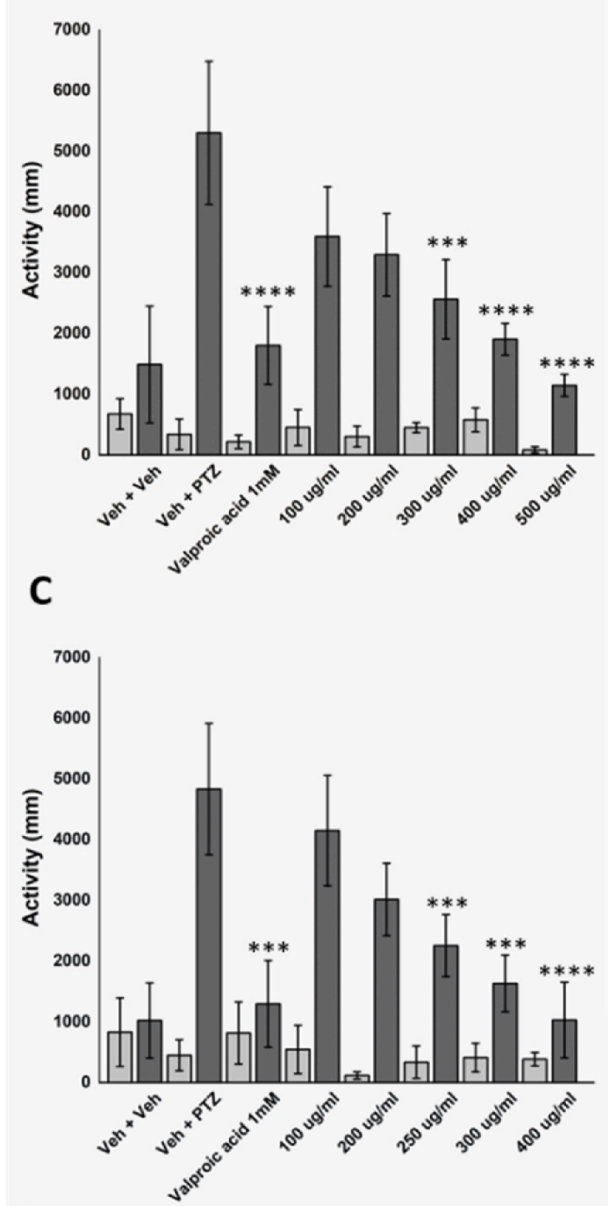

E

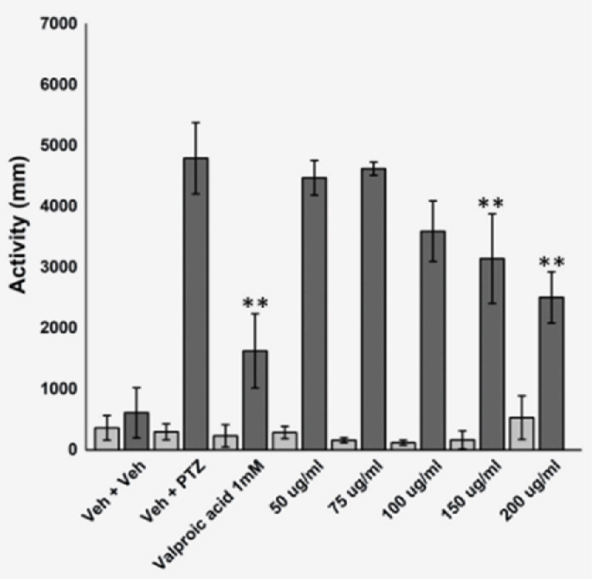

B

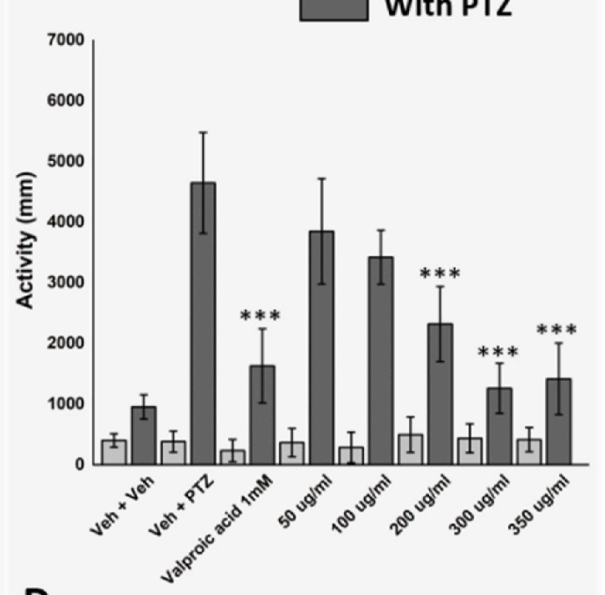

D

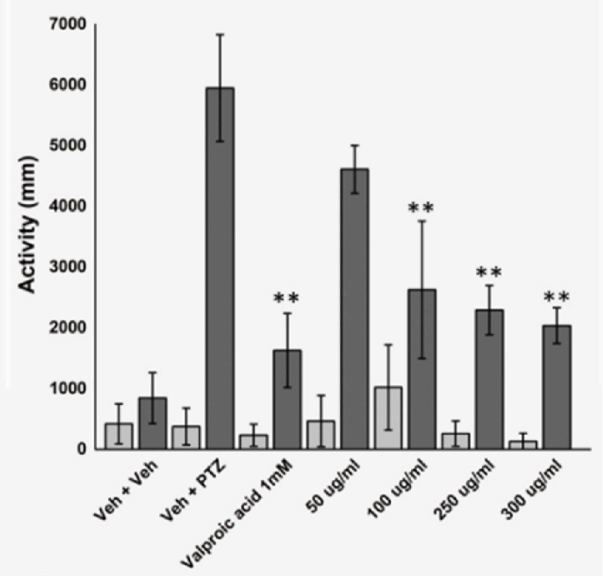

$\mathbf{F}$

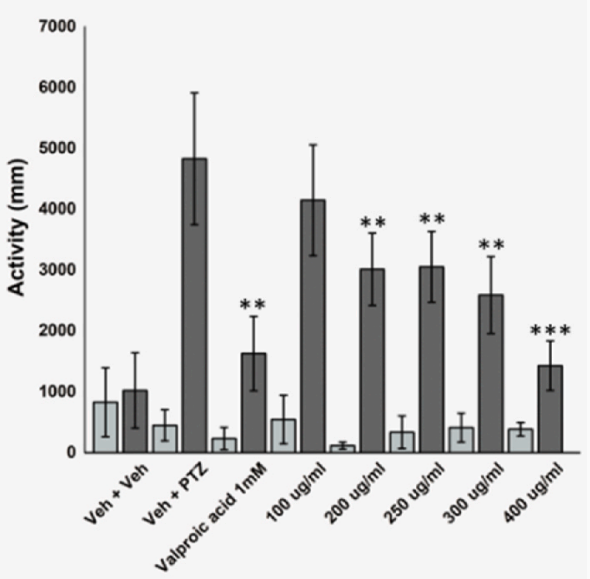

Fig. 2. Concentration-dependent effects of the six active crude extracts on the seizure-like activity (total distance moved, $\mathrm{mm}$ ) of the zebrafish larvae, over a 30 min video tracking period in the absence and presence of PTZ (20 mM). A: $R$. caffra aqueous extract. B: $R$. caffra methanolic extract. C: $W$. somnifera methanolic extract, D: $R$. vomitoria methanolic extract. E: Annona senegalensis aqueous extract, F: Costus afer aqueous extract. Asterisks indicate the level of significance compared to the negative control: $* \mathrm{P}<0.1$, ** $\mathrm{P}<0.01$, *** $\mathrm{P}<$ 0.001 and $* * * * \mathrm{P}<0.0001$. Tests were carried out in triplicate, results were expressed as mean plus standard error of the mean (SEM) of the total distance tracked in a 30 min period. Veh, vehicle, $0.3 X$ Danieau's medium with $1 \%$ DMSO, PTZ, pentylenetetrazole. of the plants (e.g. alkaloids, tannins) were found in non-polar extracts of the plants in the current study. Aqueous extracts proved to be less toxic to the larvae than extracts from non-polar solvents: It was noted that as the polarity of the extraction solvent decreased, the MTC also decreased. The findings from the current study with respect to anti-epileptic herbal medicines are in agreement with this observation.

These findings are encouraging contributory evidence for safety, given that traditional medicinal preparations are usually aqueous extracts administered in the form of decoctions and teas. It is fortuitous that fewer toxic principles are obtained by using water, the universal 
A

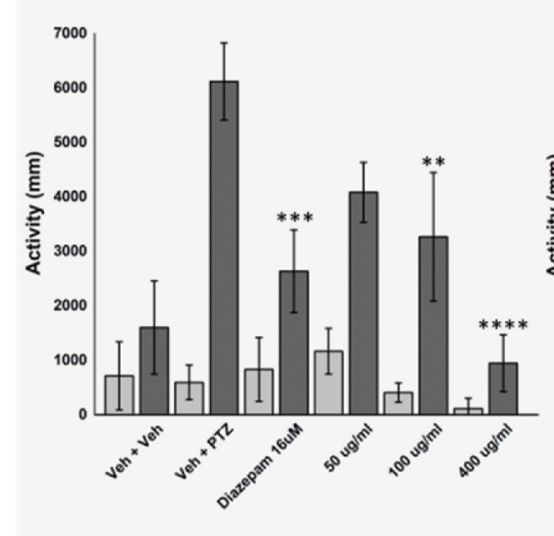

B

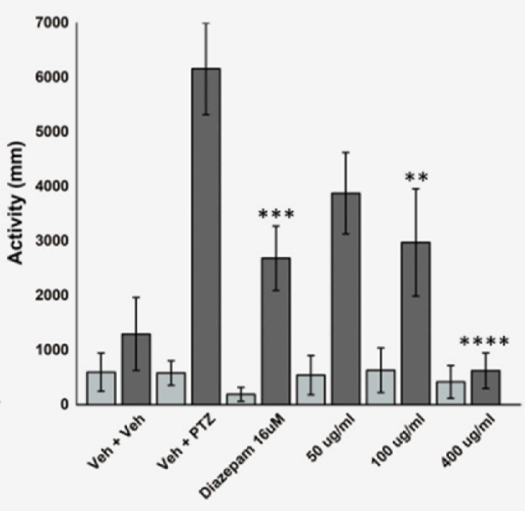

C
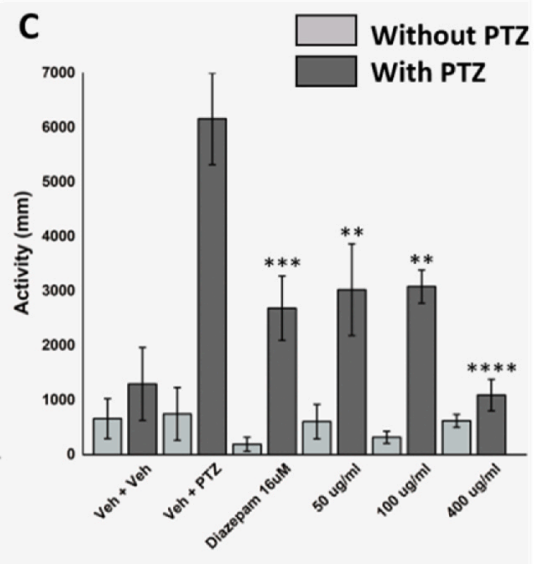

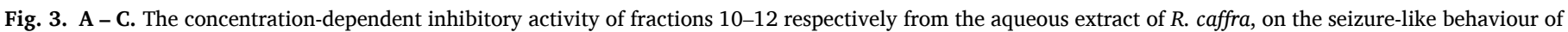

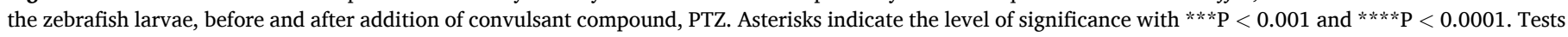
were carried out in triplicate; results expressed as mean \pm SEM of the total distance tracked in a 30 min period.

non-toxic neutral solvent, in contrast to extraction with organic solvents, which are known to be toxic, often directly proportional to concentration, yielding an extract matrix of toxic compounds. Maximum tolerated concentrations were determined for all fractions of the crude extracts, with the highest MTC value of $500 \mu \mathrm{g} / \mathrm{mL}$ recorded in the methanolic (fractions 7-12) and aqueous (fractions 15-19, 21, 24) fractions of Rauvolfia caffra. The lowest tolerated concentration as determined in the MTC study was $10 \mu \mathrm{g} / \mathrm{mL}$ for aqueous fraction 25 of Rauvolfia caffra. Withania somnifera displayed higher toxicity in the larvae, with the highest MTC of $500 \mu \mathrm{g} / \mathrm{mL}$ recorded for only two methanolic fractions, fractions 30 and 31. Ten Withania somnifera methanolic fractions were too toxic, even at the lowest concentration applied, $10 \mu \mathrm{g} / \mathrm{mL}$, for any MTC to be determined. The general toxicity profile of fractions was found to be similar to that of the crude extracts.

Two compounds, denoted as $m / z 323$ and $m / z 325$ were isolated from Rauvolfia caffra methanolic extracts, and their MTC values determined. Compound $m / z 323$ was recorded as having an MTC value of $200 \mu \mathrm{g} / \mathrm{mL}$, while compound $m / z 325$ had a MTC value of $400 \mu \mathrm{g} / \mathrm{mL}$. The toxicity profile of compound $m / z 323$, the most bioactive compound with respect to locomotor activity reduction, offers a wide range of concentrations suitable for future concentration-response studies.

\subsubsection{Bio-activity guided fractionation}

Of the 70 extracts assessed for locomotor inhibitory activity, six extracts exhibited an apparently concentration-dependent reduction in the seizure-like behaviour of larvae after treatment with PTZ (Fig. 2). The crude extract with the highest activity was the aqueous extract of Rauvolfia caffra (Fig. 2 A and B). An apparent concentration-dependent antiseizure activity, indicative of an increase in bioactivity, was observed compared to negative control, from $50 \mu \mathrm{g} / \mathrm{mL}$ to the highest concentration tested, $350 \mu \mathrm{g} / \mathrm{mL}$. Statistical significance $(\mathrm{P}<0.001)$ was observed for extracts concentrations $200 \mu \mathrm{g} / \mathrm{mL}, 300 \mu \mathrm{g} / \mathrm{mL}$ and 350 $\mu \mathrm{g} / \mathrm{mL}$ (Fig. $2 \mathrm{~A}$ ). A similar apparent concentration-dependent effect was also observed for the methanolic extract of Rauvolfia caffra (Fig. 2 B), with a highly statistically significant difference exhibited for crude extract concentrations $300 \mu \mathrm{g} / \mathrm{mL}(\mathrm{P}<0.001), 400 \mu \mathrm{g} / \mathrm{mL}$ and $500 \mu \mathrm{g} /$ $\mathrm{mL}$ (both $\mathrm{P}<0.0001$ ).

Withania somnifera, methanolic (Fig. 2 C) extract also displayed a concentration-dependent effect in the PTZ test, with a highly statistically significant difference between negative control and extracts at $250 \mu \mathrm{g} /$ $\mathrm{mL}(\mathrm{P}<0.001), 300 \mu \mathrm{g} / \mathrm{mL}(\mathrm{P}<0.0001)$ and $400 \mu \mathrm{g} / \mathrm{mL}(\mathrm{P}<0.0001)$. At concentrations of $100 \mu \mathrm{g} / \mathrm{mL}$ and $200 \mu \mathrm{g} / \mathrm{mL}$ there was no significant difference between control and crude extract.

Rauvolfia vomitoria, Annona senegalensis and Costus afer (Fig. 2D-F) crude extracts exhibited statistically significant effect in the PTZ test in extract concentrations from $100 \mu \mathrm{g} / \mathrm{mL}, 150 \mu \mathrm{g} / \mathrm{mL}$ and $200 \mu \mathrm{g} / \mathrm{mL}(\mathrm{P}$ $<0.01$ for all three plants), respectively.

While all six extracts showed promising activity, given their marginally superior activity, the methanolic extracts of $R$. caffra and Withania somnifera were selected for further investigation. In the PTZ assay no significant effect was observed after treatment with the aerial parts of the following plants Afzelia africana, Anchomanes difformis, Aframomum melequeta, Bersama Lucens, Dioscorea dregeana, Elephantorrhiza elephantina, Garcinia kola, Hibiscus sabdariffa, Landolphia owariensis, Leonotis leonurus, Mondia whitei, Synaptolepis kirkii, Withania somnifera. In Xylopia aethiopica no bioactivity assays were conducted because of the high toxicity of the plant, which precluded determination the MTC even at a concentration as low as $10 \mu \mathrm{g} / \mathrm{mL}$. Interestingly, increased pro-convulsant activity was recorded with Afzelia africana (ethyl acetate extract) and Anchomanes difformis (aqueous extract), where locomotor activity, after the induction of seizures by PTZ, was further increased, suggesting that these plant extracts possibly exacerbate the seizure severity.

\subsection{Assessment of the anticonvulsant activity of fractions and isolated compounds}

\subsubsection{Maximum tolerated concentration (MTC) of fractions}

The fractionation of Rauvolfia caffra and Withania somnifera extracts into 1-min aliquots using prep-HPLC yielded 44 fractions. The MTC values for all 25 fractions from Rauvolfia caffra were determined. The lowest fraction MTC values were for Rauvolfia caffra, aqueous and methanolic fractions, recorded at $10 \mu \mathrm{g} / \mathrm{mL}$ and the highest recorded $500 \mu \mathrm{g} / \mathrm{mL}$. For Withania somnifera MTC values could be determined for only nine of the 19 fractions. The remaining ten were highly toxic over the concentration range tested. It was also observed that in the majority of the Withania somnifera fractions the MTC values were relatively low compared to those of Rauvolfia caffra, indicative of potentially higher toxicity for Withania somnifera. No trend was recorded in the MTC values between water and methanolic fractions, with potential toxicity thus similar to that of the crude extracts.

\subsubsection{Inhibition of seizure-like behaviour by Rauvolfia caffra and Withania somnifera fractions: pentylenetetrazole (PTZ) assay in 6-dpf zebrafish larvae}

Selected crude extracts were subjected to time-based fractionation using preparative HPLC-MS into 1-min aliquots to yield 44 fractions. The 44 non-toxic fractions from Rauvolfia caffra and Withania somnifera 


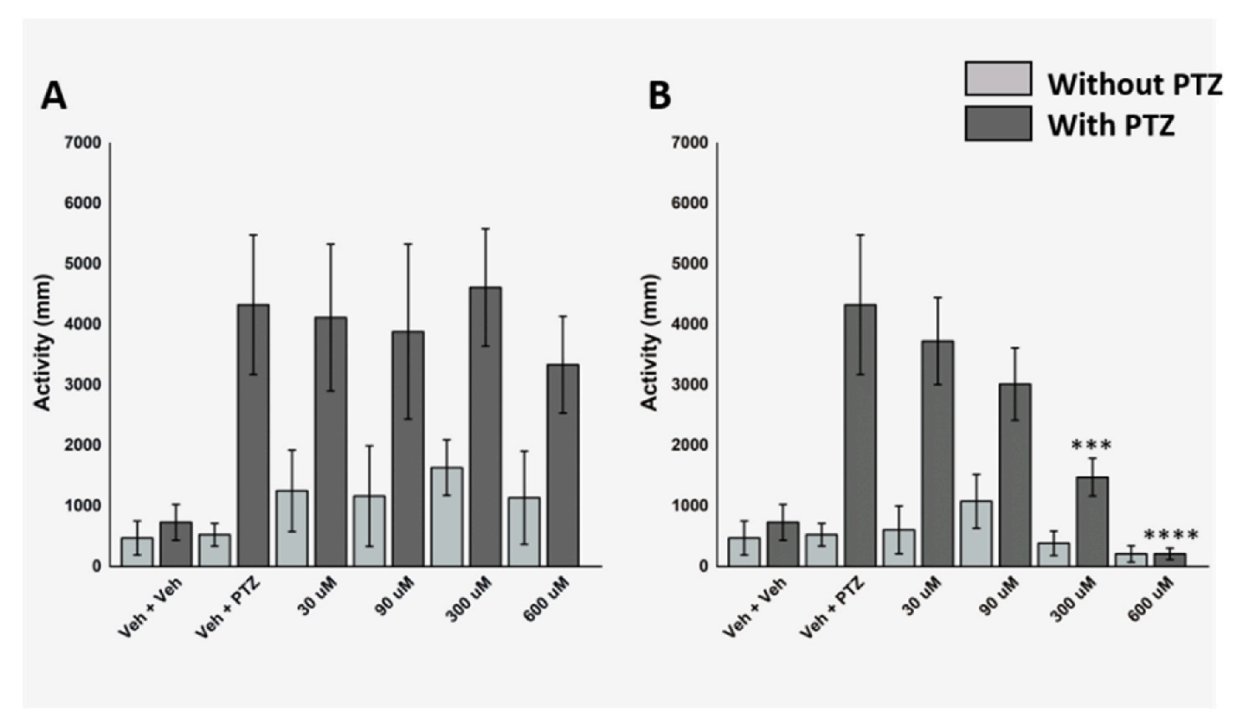

Fig. 4. The concentration-dependent inhibitory activity of compound 1 (A) and compound 2 . (B) on the seizure-like behaviour of the zebrafish larvae, before and after addition of convulsant compound, PTZ. These data indicate that while the activity of the crude extract is not attributable to compound $\mathbf{1}$, compound 2 does represent an encouraging hit antiseizure compound. Asterisks indicate the level of significance with ***P $<0.001$ and $* * * * \mathrm{P}<0.0001$. Tests were carried out in triplicate; results expressed as mean \pm SEM of the total distance tracked in a 30 min period.

revealed five fractions (fractions 8 to 12 ) that displayed significant antiepileptic effect from the Rauvolfia caffra methanolic fraction, with fractions 10-12 in particular displaying the most significant anti-seizure activity (Fig. $3 \mathrm{~A}-\mathrm{C}$ ).

Neither the Rauvolfia caffra aqueous fractions (fractions 13-25) nor the Withania somnifera methanolic fractions (fractions 26-44) displayed any significant effect compared to negative control.

Fig. 3 shows the results of the PTZ assay on Rauvolfia caffra methanolic fractions. Three fractions, fractions 10, 11 and 12 displayed promising bioactivity, with fraction 12 active from the lowest concentration tested, $50 \mu \mathrm{g} / \mathrm{mL}(\mathrm{P}<0.01)$, whereas fractions 10 and 11 were potentially bioactive from a concentration of $100 \mu \mathrm{g} / \mathrm{mL}(\mathrm{P}<0.01)$ compared to the negative control. A statistically significant bioactive effect was observed in fractions 10, 11 and 12 at a concentration of 400 $\mu \mathrm{g} / \mathrm{mL}(\mathrm{P}<0.0001)$.

These results indicated activity for all Rauvolfia caffra fractions tested and further optimally designed studies would be required for concentration-activity response confirmation.

\subsubsection{Maximum tolerated concentration (MTC) of isolated compounds}

Two compounds, $m / z 323$ and $m / z 325$ were isolated from Rauvolfia caffra methanolic extracts, and their MTC values determined as $200 \mu \mathrm{g}$ / $\mathrm{mL}$ and $400 \mu \mathrm{g} / \mathrm{mL}$, respectively.

3.2.4. Inhibition of seizure-like behaviour by the isolated compounds: pentylenetetrazole (PTZ) assay in 6-dpf zebrafish larvae

An apparently concentration-dependent bioactivity was observed (Fig. 4, A and B) with compound $m / z 323$ (compound 2), compared to the negative control, with statistically significant activity displayed at $100 \mu \mathrm{g} / \mathrm{mL}$ and $200 \mu \mathrm{g} / \mathrm{mL}$ treatment concentrations $(\mathrm{P}<0.001$ and $\mathrm{P}$ $<0.0001$ respectively). Compound $M / z 325$ (compound 1) did not display significant bioactivity with respect to locomotor activity reduction.

\subsection{Chemical profiling of bioactive Rauvolfia caffra crude extract, fractions and compounds}

The UPLC-MS profile of the bioactive methanolic crude extract of Rauvolfia caffra is provided in Fig. 5 and highlighted are the peaks that were targeted for isolation since these peaks were common to both the crude extract and certain fractions. Guided by this observation the common peaks were targeted for isolation, namely $\mathrm{m} / \mathrm{z} 323, \mathrm{~m} / \mathrm{z} 325$, $\mathrm{m} / z$ 335. It was possible to successfully isolate $\mathrm{m} / z 323$ and, $\mathrm{m} / z 325$ to $100 \%$ purity levels, the percentage yields were $0.032 \%$ and $0.014 \%$
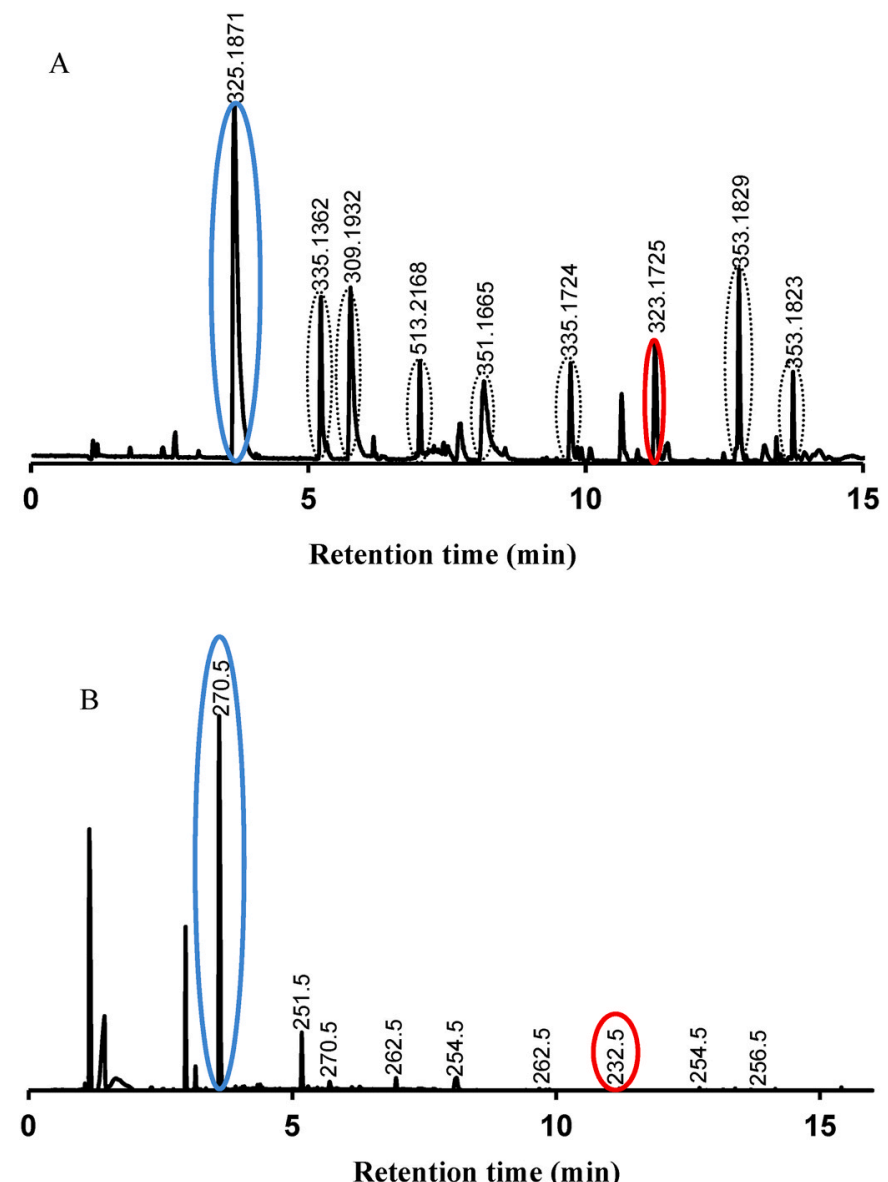

Fig. 5. UPLC-MS (A) and UPLC-MS-PDA (B) profile of Rauvolfia caffra methanolic crude extract. Highlighted are peaks of compounds targeted for isolation, and in colour peaks of compounds isolated: red $=m / z 323$ and blue $=m / z 325$. (For interpretation of the references to colour in this figure legend, the reader is referred to the Web version of this article.)

respectively.

Compound $m / z 323$, present in the crude extract $(\mathrm{RT}=11.26 \mathrm{~min}$ ) and fractions 10 to 12 , was elucidated as pleiocarpamine, a known compound isolated from Rauvolfia caffra stem bark (Nasser and Court, 


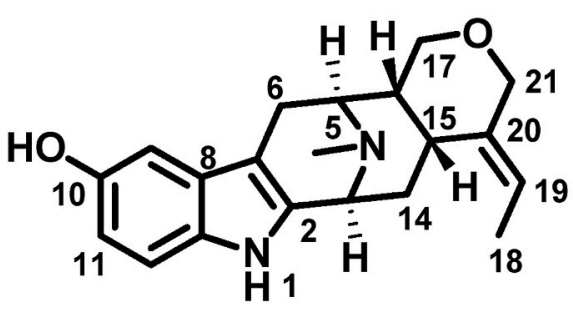

1. Rauverine $H$

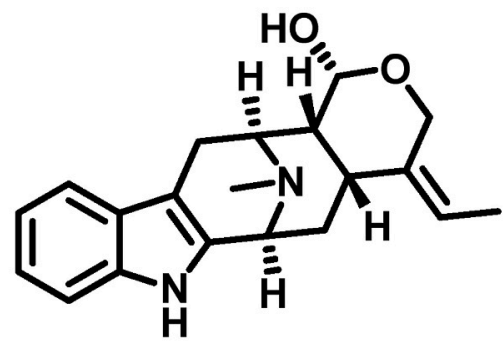

3. Rauverine A

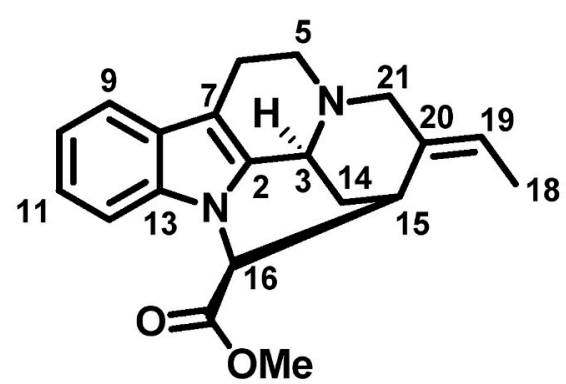

2. Pleiocarpamine

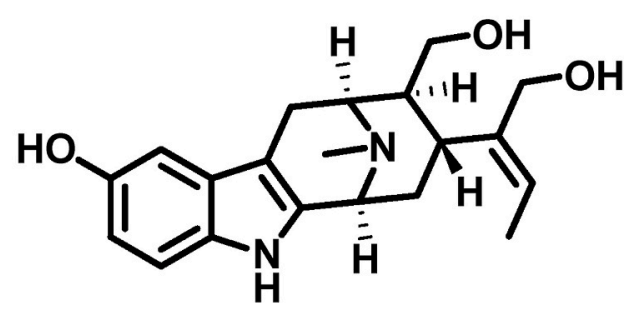

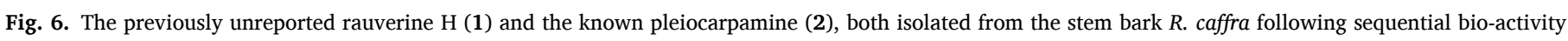

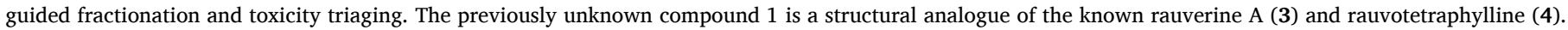

Table 3

The identification of compounds isolated from Rauvolfia caffra.

\begin{tabular}{|c|c|c|c|c|c|}
\hline $\begin{array}{l}\text { Compound (molecular } \\
\text { weight, } \mathrm{g} / \mathrm{mol} \text { ) }\end{array}$ & Extract & $\begin{array}{l}\text { UPLC-MS } \\
{[\mathrm{M}+\mathrm{H}]^{+}} \\
\mathrm{m} / \mathrm{z}\end{array}$ & $\begin{array}{l}\mathrm{R}_{\mathrm{t}} \\
(\mathrm{min})\end{array}$ & $\begin{array}{l}\text { Major } \\
\text { fragments }\end{array}$ & $\begin{array}{l}\lambda_{\max } \\
(\mathrm{nm})\end{array}$ \\
\hline $\begin{array}{l}\text { pleiocarpamine } \mathrm{a}^{\mathrm{a} b \mathrm{~b}} \\
\text { (322.4) }\end{array}$ & $\begin{array}{l}\text { Methanolic } \\
\text { crude } \\
\text { extract }\end{array}$ & 323.1725 & 11.26 & $\begin{array}{l}294.1025 \\
263.1111 \\
234.0868 \\
180.0664 \\
144.0506\end{array}$ & $\begin{array}{l}232.5 \\
283.5\end{array}$ \\
\hline $\begin{array}{c}\text { rauverine } \mathrm{H}^{\mathrm{c}} \\
(324.2)\end{array}$ & $\begin{array}{l}\text { Methanolic } \\
\text { crude } \\
\text { extract }\end{array}$ & 325.1871 & 3.66 & $\begin{array}{l}307.1362 \\
277.0835 \\
152.0771 \\
135 . .0761\end{array}$ & $\begin{array}{l}220.5 \\
270.5\end{array}$ \\
\hline
\end{tabular}

KEY.

a Identified tentatively from the UPLC-MS data.

b Reported in the plant previously.

c Identified from NMR data, not previously reported.

1984). Compound $m / z 325$ present in the crude extract ( $\mathrm{RT}=3.66 \mathrm{~min})$ and all fractions, was identified as a pentacyclic alkaloid and given the trivial name of rauverine $\mathrm{H}$. A previously reported hydroxyl isomer of this compound, rauverine A (3, Fig. 6), was isolated from twigs of Rauvolfia verticillata (Lour.) Baill (Zhang et al., 2013) and a quadricyclic analogue, rauvotetraphylline A (4, Fig. 6) was earlier reported by Gao et al. (2012).

UPLC-MS data used to tentatively identify compounds isolated from Rauvolfia caffra is summarised in Table 3. Chromatograms and UV spectra confirming the purity of isolates are provided as supplementary data (S1.3-1.4).

Subsequent UPLC-MS chemical profiling was conducted in order to isolate and identify the chemical entities possibly responsible for this activity. A molecular ion at $325.1926 \mathrm{~m} / z[\mathrm{M}+\mathrm{H}]^{+}(1)$ was identified in the crude extract and all the active fractions, while a molecular ion at
$323.1760 \mathrm{~m} / \mathrm{z}[\mathrm{M}+\mathrm{H}]^{+}(2)$, which was present in the crude extract, was found in fractions 10-12. These chemical constituents were isolated from each of the appropriate fractions, where they were again subjected to toxicity and seizure-like behaviour inhibition assessment. Compounds $\mathbf{1}$ and $\mathbf{2}$ were found to have MTC values of receptivity. Furthermore, while compound $\mathbf{1}$ did not display significant activity, compound $\mathbf{2}$ was found to have a statically significant effect in the suppression of zebrafish seizure-like activity, at concentrations well below its MTC (Fig. 4 A and B). Chromatograms confirming the purity of isolates are provided as supplementary data (spectral data1.3 and 1.4).

\subsection{Structural elucidation of compounds isolated from Rauvolfia caffra}

The interpretation of 1D and 2D NMR spectra of the two compounds, $\mathrm{m} / \mathrm{z} 325$ (compound 1) and $M / z 323$ (compound 2), isolated from Rauvolfia caffra stem bark methanol crude extract is provided in this section. Compounds $m / z 325$ (compound 1 ) and $m / z 323$ (compound 2) were identified as tryptoline derivatives, the previously unreported rauverine $\mathrm{H}$ (1, Fig. 6), and the known compound pleiocarpamine (2, Fig. 6). ${ }^{1} \mathrm{H}$ and ${ }^{13} \mathrm{C}$ assignments for compounds $m / z 323$ and $m / z 325$ are presented in Table 4. Spectra and key ${ }^{1} \mathrm{H}-{ }^{1} \mathrm{H}$ correlation spectroscopy correlation (COSY) and heteronuclear multiple-bond correlation spectroscopy (HMBC) configurations pertaining to pleiocarpamine (Figs. 6 and 7 (1)) and rauverine $\mathrm{H}$ (Figs. 6 and 7 (2)) are supplied as supplementary data. UPLC-MS data and NMR data are summarised in Table 4 and briefly discussed as a conclusion to this section. Chromatographs and PDA spectra are provided as supplementary data (Spectral data 1.3 and 1.4).

The deconvoluted mass of the molecular ion of compound 1 $\left(325.1926 \mathrm{~m} / \mathrm{z}[\mathrm{M}+\mathrm{H}]^{+}\right.$) corresponded to a molecular formula of $\mathrm{C}_{20} \mathrm{H}_{24} \mathrm{~N}_{2} \mathrm{O}_{2}$, whose double bond equivalent (DBE) was calculated at 10 . Inspection of the downfield region of the ${ }^{1} \mathrm{H}$ NMR spectrum in conjunction with the HSQC spectrum revealed the presence of a broad 
Table 4

${ }^{1} \mathrm{H}(500 \mathrm{MHz})$ and ${ }^{13} \mathrm{C}(125 \mathrm{MHz})$ assignment of compounds 1 and 2 in CD3OD.

\begin{tabular}{|c|c|c|c|c|c|c|c|c|c|c|}
\hline \multicolumn{6}{|l|}{1} & \multicolumn{5}{|l|}{2} \\
\hline Position & $\delta_{\mathrm{H}}$ & & & $\mathrm{J}(\mathrm{Hz})$ & $\delta_{\mathrm{C}}$ & $\delta_{\mathrm{H}}$ & & & $\mathrm{J}(\mathrm{Hz})$ & $\delta_{\mathrm{C}}$ \\
\hline $1_{2}$ & 8.57 & brs & $1 \mathrm{H}$ & & 133.1 & & & & & 136.7 \\
\hline 3 & $4.84^{\mathrm{a}}$ & & $1 \mathrm{H}$ & & 62.5 & $4.05-4.04$ & $\mathrm{~m}$ & $1 \mathrm{H}$ & & 51.7 \\
\hline 4 & 3.52 & $\mathrm{t}$ & $1 \mathrm{H}$ & 5.0 & 66.9 & 3.39 & ddd & $1 \mathrm{H}$ & $12.9,9.9,2.5$ & 50.9 \\
\hline $5 \mathrm{~b}$ & & & & & & 2.38 & dt & $1 \mathrm{H}$ & $12.9,8.5$ & \\
\hline $6 a$ & 3.26 & dd & $1 \mathrm{H}$ & $17.3,5.0$ & 25.3 & 3.21 & ddd & $1 \mathrm{H}$ & $\begin{array}{l}15.7,8.5, \\
2.5\end{array}$ & 20.9 \\
\hline $6 \mathrm{~b}$ & 3.02 & dd & $1 \mathrm{H}$ & 17.3 & & 2.80 & ddd & $1 \mathrm{H}$ & $\begin{array}{l}\text { 15.7,9.9, } \\
8.5\end{array}$ & \\
\hline 7 & & & & & 101.1 & & & & & 109.7 \\
\hline 8 & & & & & 128.2 & & & & & 129.6 \\
\hline 9 & 6.87 & $\mathrm{~d}$ & $1 \mathrm{H}$ & 2.2 & 103.5 & $7.53-7.52$ & $\mathrm{~m}$ & $1 \mathrm{H}$ & & 119.4 \\
\hline 10 & & & & & 152.3 & $7.09-7.06$ & $\mathrm{~m}$ & $2 \mathrm{H}$ & & 121.1 \\
\hline 11 & 6.75 & dd & $1 \mathrm{H}$ & $8.6,2.2$ & 113.8 & $7.09-7.06$ & $\mathrm{~m}$ & $2 \mathrm{H}$ & & 122.1 \\
\hline 12 & 7.21 & $\mathrm{~d}$ & $1 \mathrm{H}$ & 8.6 & 113.2 & $6.99-6.97$ & $\mathrm{~m}$ & $1 \mathrm{H}$ & & 113.6 \\
\hline 13 & & & & & 133.5 & & & & & 139.4 \\
\hline $14 \mathrm{a}$ & 2.50 & $\mathrm{t}$ & $1 \mathrm{H}$ & 11.6 & 33.4 & 2.20 & ddd & $1 \mathrm{H}$ & $13.6,4.2,2.3$ & 28.3 \\
\hline $14 \mathrm{~b}$ & $2.13-2.19$ & $\mathrm{~m}$ & $2 \mathrm{H}$ & & & 2.63 & $\mathrm{dt}$ & $1 \mathrm{H}$ & $13.6,3.5$ & \\
\hline 15 & 3.10 & $\mathrm{~d}$ & $1 \mathrm{H}$ & 3.7 & 27.4 & 3.62 & $\mathrm{~m}$ & $1 \mathrm{H}$ & & 34.3 \\
\hline 16 & $2.13-2.19$ & $\mathrm{~m}$ & $1 \mathrm{H}$ & 7.3 & 45.0 & 5.33 & $\mathrm{~d}$ & $1 \mathrm{H}$ & 4.1 & 62.0 \\
\hline 17 & 3.55 & $d$ & $2 \mathrm{H}$ & 7.3 & 63.8 & & & & & 170.5 \\
\hline 18 & 1.71 & $\mathrm{~d}$ & $3 \mathrm{H}$ & 6.7 & 12.9 & 1.53 & ddd & $3 \mathrm{H}$ & $6.8,2.0$ & 12.8 \\
\hline 19 & 5.64 & $\mathrm{q}$ & $1 \mathrm{H}$ & 6.7 & 122.1 & 5.39 & qd & $1 \mathrm{H}$ & $6.8,2.0$ & 125.7 \\
\hline 20 & & & & & 129.1 & & & & & 133.5 \\
\hline $21 a$ & 4.41 & $\mathrm{~d}$ & $1 \mathrm{H}$ & 15.4 & 65.8 & 2.74 & $\mathrm{~d}$ & $1 \mathrm{H}$ & 13.1 & 57.3 \\
\hline $21 b$ & 4.19 & $\mathrm{~d}$ & $1 \mathrm{H}$ & 15.4 & & 1.87 & $\mathrm{dt}$ & $1 \mathrm{H}$ & $13.1,2.0$ & \\
\hline Me & 3.08 & $\mathrm{~s}$ & $3 \mathrm{H}$ & & 48.1 & 3.61 & $\mathrm{~s}$ & $3 \mathrm{H}$ & & 52.6 \\
\hline
\end{tabular}

a Assigned by HSQC.

singlet $\left(\delta_{\mathrm{H}}\right.$ 8.57) unassociated to a carbon atom, consistent with an indole $\mathrm{NH}$, as well as three aromatic $\mathrm{CH}$ signals $\delta_{\mathrm{H}} 7.21(1 \mathrm{H}, \mathrm{d}, J=8.6$ $\mathrm{Hz}), \delta_{\mathrm{H}} 6.87(1 \mathrm{H}, \mathrm{d}, J=2.2 \mathrm{~Hz})$ and $\delta_{\mathrm{H}} 6.75,(1 \mathrm{H}, \mathrm{dd}, J=8.6,2.2 \mathrm{~Hz})$ whose coupling constants in addition to COSY correlations allowed us to assign an AMX system consistent with a substituted indole. All three of these proton signals correlated though HMBC with a quaternary carbon $\left(\delta_{C}\right.$ 152.3), whose chemical shift, and lack of further NMR correlations was indicative of a hetero aromatic substituent. The ${ }^{13} \mathrm{C}$ spectrum contained two quaternary carbon signals at $\delta_{C} 133.5$ and $\delta_{C} 128.2$, consistent with signals for C-13 and C-8 respectively for previously reported tryptoline derivatives. ${ }^{15,16}$ The aromatic proton signal at $\delta_{\mathrm{H}} 7.21$ was assigned to $\mathrm{H}-12$ based on an HMBC correlation to the carbon signal at $\delta_{\mathrm{C}} 128.2$, while similarly, the positions of the proton signals at $\delta_{\mathrm{H}} 6.87$ $(\mathrm{H}-9)$ and $\delta_{\mathrm{H}} 6.75(\mathrm{H}-11)$ were assigned trough corresponding HMBC correlations with the carbon signal at $\delta_{C} 133.5$. This information in conjunction with the coupling constants of these position allowed us to unambiguously assign the putative heteroatomic indole substituent to C10. An HMBC correlation between $\mathrm{H}-9$ and a quaternary carbon signal at $\delta_{\mathrm{C}} 101.1$ allowed us to assign this carbon signal to C-7. Furthermore, methylene protons at $\delta_{\mathrm{H}} 3.26(\mathrm{H}-6 \mathrm{a})$ and $\delta_{\mathrm{H}} 3.02(\mathrm{H}-6 \mathrm{~b})$ and a methine proton $3.52(\mathrm{H}-5)$, which correlated to each other through COSY, both correlated through HMBC to the carbon signal assigned to C-7. Furthermore, the H-6 protons correlated to a quaternary carbon signal at $\delta_{\mathrm{C}} 133.1$, which we assigned to C-2. COSY correlations between $\mathrm{H}-5$ and a methine signal at $\delta_{\mathrm{H}} 2.17(\mathrm{H}-16)$ and subsequently between the $\mathrm{H}-16$ resonance and a methylene resonance at $\delta_{\mathrm{H}} 3.55(\mathrm{H}-17)$, allowed us to establish connectivity between these positions. This assignment was supported by corresponding HMBC correlations between positions 6 and 16 as well as 5 and 17. A further COSY correlation, between the H-16 methine and a methine signal at $\delta_{\mathrm{H}} 3.10(\mathrm{H}-15)$ tentatively allowed us to assign these positions as a ring juncture. Corresponding HMBC correlations between positions 15 and 17 as well as H-15 and C-5 supported this assignment. Sequential COSY correlations between $\mathrm{H}-15$ and a diastereotopic methylene $\left(\delta_{\mathrm{H}} 2.50,2.17, \mathrm{H}-14\right)$ followed by a methine at $\delta_{\mathrm{H}} 4.84$ (H-3) established a chain of connectivity between these resonances. A key HMBC correlation between H-14 and C-2 allowed us to confirm the formation of an additional fused ring system. Sequential HMBC correlations between $\mathrm{H}-16$ and C-14 as well as H-15 and C-3 allowed for the final assignment of these positions. A proton signal at $\delta_{\mathrm{H}}$ 5.64 (H-19) which correlated through HSQC to a carbon resonance at $\delta_{C}$ 122.1 was consistent with an alkene residue. Furthermore, a COSY correlation between $\mathrm{H}-19$ and a methyl signal $\delta_{\mathrm{H}} 1.71(\mathrm{H}-18)$ indicated the presence of an ethylidene substituent. Dual HMBC correlations between $\mathrm{H}-18, \mathrm{H}-16$ with a quaternary carbon at $\delta_{\mathrm{C}} 129.1$ (C-20), consistent with an alkene signal, indicated the possible site of attachment of the ethylidene. This tentative assignment was supported by corresponding $\mathrm{HMBC}$ correlations between positions 15 and 19. A long range COSY correlation between $\mathrm{H}-19$ and a diastereotopic methylene $\left(\delta_{\mathrm{H}}\right.$ $4.41,4.19, \mathrm{H}-21$ ), in addition to HMBC correlations between $\mathrm{H}-15,18$ and 19 with C-21, allowed us to unambiguously assign position 21 . Finally, an outstanding methylamine singlet $\left(\delta_{\mathrm{H}} 3.08\right)$ correlated through HMBC to C-5 and C-3 respectively, allowing us to position this substituent on the bridgehead nitrogen, resulting in our proposed pentacyclic structure, with 5 double bonds, which complies with our calculated DBE. Zhang et al. have previously reported a hydroxy isomer, rauverine A (3) isolated from the twigs of $R$. verticillata ${ }^{13}$ while a quadracyclic analogue, rauvotetraphylline A (4), has been reported by Gao et al. ${ }^{17}$ Accordingly we assigned this compound the trivial name rauverine $\mathrm{H}$, (Table 3, Fig. 7). While presumably compound $\mathbf{1}, \mathbf{3}$ and 4 are biosynthetically related, the relative configurations of the 4 common stereocenters as well as the $E / Z$ configuration of the double bond of compounds $\mathbf{3}$ and $\mathbf{4}$ is not congruent. The NOESY spectrum of compound 1, showed that the protons at positions 3 and 5, both possessed strong NOE correlations with the $N$-methyl resonance (Fig. 8). This suggested that all three moieties orientate in same plane, allowing us to assign a cis-relationship between 3 and 5, which was in agreement with the assignment of both compounds 3 and 4. Similarly, NOE correlations between protons 15 and 16 also suggested a cis-relationship. The absence of NOE correlations between protons 5 and 16 indicated a transrelationship between these protons. Together this data suggested that 


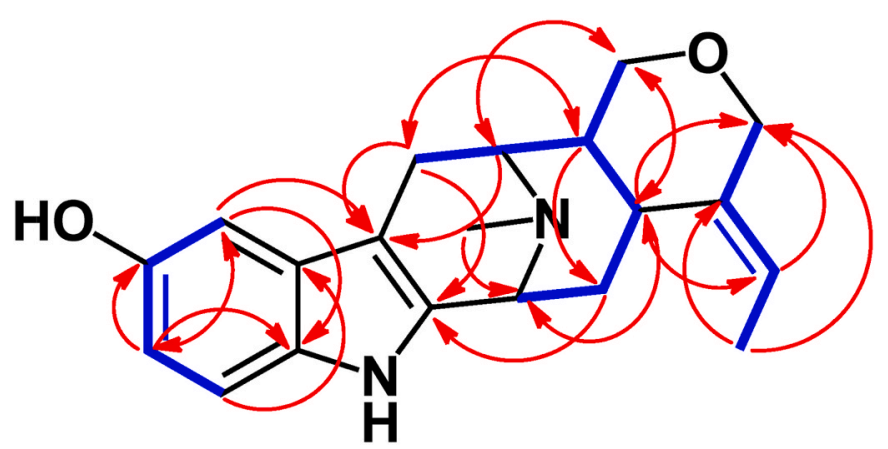

1. Rauverine $\mathbf{H}$

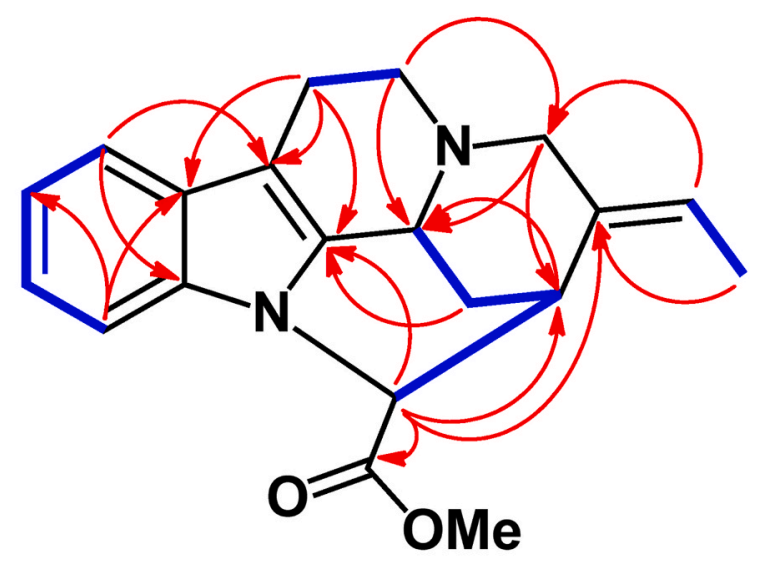

2. Pleiocarpamine

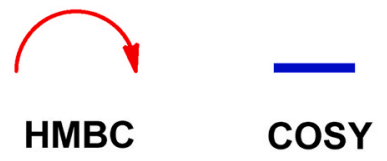

Fig. 7. Key HMBC and COSY correlations leading to the assignment of compounds $\mathbf{1}$ and $\mathbf{2}$. as rauverine $\mathrm{H}$ and pleiocarpamine respectively.

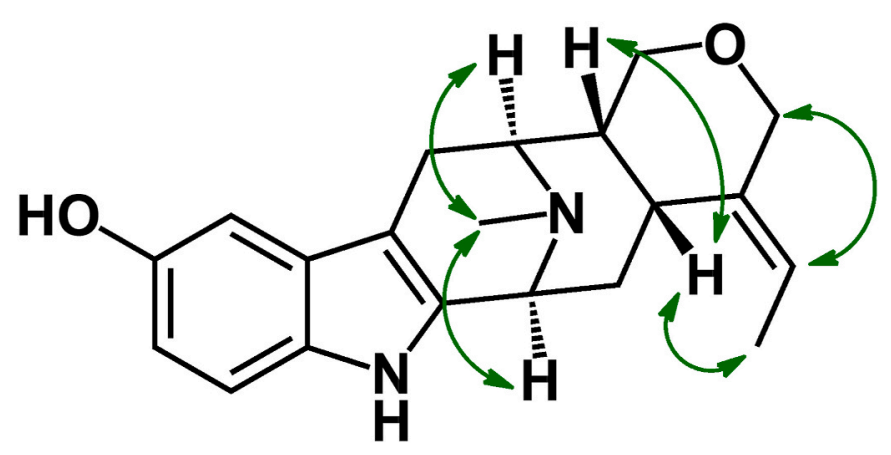

Fig. 8. Key NOE correlations for compound 1.

the relative configuration of the stereocenters was in alignment with that reported for compound 3. Finally, a strong NOE correlation between positions 18 and 15, in conjunctions with a weaker correlation between 19 and 21, allowed us to assign the double bond as $E$, which was the configuration assigned to compound 4.

Compound 2 with a molecular ion at $323.1770 \mathrm{~m} / z$ [M+H], corresponded to a molecular formula of $\mathrm{C}_{20} \mathrm{H}_{22} \mathrm{~N}_{2} \mathrm{O}_{2}$ and a double bond equivalent (DBE) of 11. Initial inspection of the 1D and 2D NMR spectral data of compound 2 indicated that similarly to compound 1 this compound also featured an ethylidene substituent $\left(\delta_{H} 5.39, \delta_{C} 125.7\right)$. An additional feature was the presence of a carbonyl resonance, $\left(\delta_{\mathrm{C}}\right.$ 170.5), which correlated through $\mathrm{HMBC}$ to a methyl signal, $\left(\delta_{\mathrm{H}} 3.61, \delta_{\mathrm{c}}\right.$ 52.6) indicating the presence of an ester moiety. The aromatic region featured three correlating signals, with a combined integral of four protons $\left(\delta_{\mathrm{H}} 7.53-7.52,1 \mathrm{H} ; 7.09-7.05,2 \mathrm{H} ; 6.99-6.97,1 \mathrm{H}\right)$ which were characteristic of an unsubstituted indole ring. Furthermore, HMBC correlations between $\mathrm{H}-12$ and $\delta_{\mathrm{C}} 129.6(\mathrm{C}-8)$ as well as $\mathrm{H}-9$ with $\delta_{\mathrm{C}}$ 139.4 (C-13) and 109.7 (C-7) were consistent with tryptoline resonances, as observed for compound 1. A diastereotopic methylene $\left(\delta_{\mathrm{H}}\right.$ $3.21,2.80$ ) correlated through $\mathrm{HMBC}$ to $\mathrm{C}-8$ and $\mathrm{C}-7$, allowing us to assign this position as H-6. Position H-5 was assigned by a COSY correlation between its diastereotopic methylene signal $\left(\delta_{\mathrm{H}} 3.39,2.38\right)$ and H-6. The H-5 resonance displayed an HMBC correlation to a carbon signal at $\delta_{\mathrm{C}} 136.7$, which we assigned as C-2, which is again a typical chemical shift for this positon on the tryptoline scaffold. Furthermore, H-5 correlated with two carbon signals at $\delta_{\mathrm{C}} 57.3$ and $\delta_{\mathrm{C}} 51.7$, which were tentatively assigned as two carbons at positions 21 and 3 , respectively. In turn, the methylene signals associated with position $21\left(\delta_{\mathrm{H}}\right.$ $2.74,1.87)$ correlated through $\mathrm{HMBC}$ to C-3. A COSY correlation between $\mathrm{H}-3\left(\delta_{\mathrm{H}} 4.05-4.04\right)$ and a diastereotopic methylene at $\delta_{\mathrm{H}} 2.63$ and $2.20(\mathrm{H}-14)$, which in turn correlated through HMBC to C-2 allowed us to assign the relative positions of these signals to the numbered positions shown. Sequential COSY correlations between $\mathrm{H}-14$ and $\mathrm{H} 15\left(\delta_{\mathrm{H}} 3.62\right)$ followed by $\mathrm{H}-16\left(\delta_{\mathrm{H}} 5.33\right)$ allowed us to assign their relative relationship. This relationship assignment was supported by HMBC correlations between $\mathrm{H}-16$ and $\mathrm{C}-14$ and $\mathrm{H}-15$ and C-3. Both $\mathrm{H}-21$ and H-16 correlated to the ethylidene attachment carbon signal (C-20) at $\delta_{\mathrm{C}} 133.5$, while a further HMBC correlation between C-21 and $\delta 5.39$ (H-19) allowed us to assign the position of attachment of the ethylidene substituent. HMBC correlations between $\mathrm{H}-16$ and the $\mathrm{C}-17$ carbonyl as well as a methyl signal at $\delta_{\mathrm{H}} 3.61$, allowed us to place the methyl ester. Finally, an HMBC correlation between H-16 and C-2, allowed us to complete the 5th ring, and allowed us to assign compound $\mathbf{2}$ as the tetracyclic tryptoline alkaloid pleiocarpamine ${ }^{18}$ (Table 3, Fig. 6).

\section{Summary and Conclusions}

To validate the traditional use of medicinal plants for the treatment of epilepsy and related CNS disorders, adequate scientific evidence is required. In this study 20 plant species were identified from the literature for their traditional use in the treatment of various CNS conditions, including epilepsy. Toxicity assays were conducted to determine the maximum tolerated concentration in zebrafish larvae, these values were then used in the determination of concentrations to be used in subsequent bioactivity assays. Maximum tolerated concentrations varied widely amongst the plant species, ranging from $10 \mu \mathrm{g} / \mathrm{mL}$ to no toxic effect even at concentrations of $500 \mu \mathrm{g} / \mathrm{mL}$. In 120 crude extracts, MTCs were determined for 70 , with 50 extracts proving too toxic to the zebrafish larvae to establish MTC.

The PTZ assay is widely accepted as an indication of potential anticonvulsant properties of a test compound or extract (Berghmans., 2007). From a total of 20 plants tested in this study, only five plant species namely Rauvolfia caffra, Withania somnifera, Annona senegalensis, Costus afer and Rauvolfia vomitoria, showed bioactivity in the PTZ assay. The positive controls using the well-known AEDs, valproic acid (1 mM) and diazepam $(16 \mu \mathrm{M})$ suppressed PTZ-mediated increases in larval locomotor activity, indicative of anticonvulsant activity. In six of the 70 crude extracts from the plant species showing bioactivity, activity of a possible concentration-dependent nature was observed, a finding that warrants further investigation in well-designed concentration-response studies in zebrafish larvae or another model.

Rauvolfia caffra was ultimately identified as the best potential candidate for yielding anticonvulsant compounds and after bioassay and chemical profiling of the fractionated extracts, two compounds were targeted for isolation. The two compounds were identified using various 
NMR techniques; compound $m / z 323$ was identified as pleiocarpamine, a compound reported to have been isolated from the stem bark of Rauvolfia caffra Sond. (Nasser and Court, 1984). This compound has also been isolated from other plant species, such as from Alstonia angustifolia (Tan et al., 2013; Tan et al., 2014). Pleiocarpamine was reported for the first time in our study to be active against PTZ-induced seizures in zebrafish larvae. The second compound, compound $\mathrm{m} / \mathrm{z} 325$, was structurally elucidated. This compound has been assigned the trivial name rauverine $\mathrm{H}$, an analogue of rauvotetraphylline A. Of these two compounds, pleiocarpamine exhibited potential anticonvulsant activity in the PTZ assay in zebrafish larvae. The most active extracts, fractions and resultant isolated pure compound were all from Rauvolfia caffra, one of the 20 of 80 species that belong to the Apocynaceae family that are indigenous to Africa (Kayani, 1977).

The work presented in this study supports the assertion of Challal et al. (2014), that a combination of modern techniques such as preparative HPLC with an in vivo model such as a zebrafish larval model, is a new strategy in rapid identification and efficient isolation of bioactive compounds from plants.

Certain limitations to this study need to be recognised, as highlighted by Afrikanova et al. (2013), locomotor activity should be used as a primary in vivo assay and follow-up assays are essential to support and confirm results. As a recommendation, the potential anticonvulsant activity shown by the compounds isolated from Rauvolfia caffra needs to be confirmed by electrophysiological studies and assays in different models, such as rodents. The activity shown by the isolated compound, pleiocarpamine warrants further investigation. Follow up investigations such as molecular docking to confirm the binding of the identified compound to specific receptors implicated in epileptogenesis, is highly recommended. It should be noted that plants labelled as "non-active" in this study should not be dismissed as unvalidated evidence of their traditional use. Chemotypic variation is rampant in almost all plant species and for practical purposes only a single collection of each species was screened in this study and may not be representative of potentially active chemotypes. Furthermore, although the zebrafish model has emerged as a valid first-pass screening model, with a response to AEDs with different modes of action, the technique does impose inherent limitations, such as the solubility of extracts and molecules in an aqueous environment (irrespective of the use of surfactants). Thirdly, epilepsy is a complex condition with numerous types of seizure manifestations. The plants selected for this study may exert their apparent anti-convulsant effect through various other mechanisms, or have sedative effects. As with all in vivo models adequate validation and confirmation of activity using other models is necessary. This study underlines the value of ethnobotany-guided drug discovery for the rapid identification of therapeutically active phytochemicals and provides scientific evidence to support the use of Rauvolfia caffra as an anti-epileptic traditional medicine. It also highlights the potential of the zebrafish PTZ assay in rapidly identifying bioactive small compounds of natural origin, including also identification of new novel compounds.

\section{Acknowledgements}

The project was supported by the National Research Foundation of South Africa Grant (111438) awarded to Chipiti T, Enslin G (Grant TTK150723129831), Viljoen AM (86923) and the South African Medical Research Council (Herbal Drugs Research Unit). Clinton Veale gratefully acknowledges financial support in the form of a Future Leaders - African Independent Research (FLAIR), research fellowship. The FLAIR Fellowship Programme is a partnership between the African Academy of Sciences and the Royal Society funded by the UK Government's Global Challenges Research Fund. The African Centre for DNA Barcoding (ACDB), Department of Botany and Plant Biotechnology, University of Johannesburg, South Africa is thanked for performing the genetic studies to confirm species identities.

The authors acknowledge previous and present staff of the Zebrafish
Core Facility at the Luxembourg Centre for Systems Biomedicine for their husbandry and technical support for the performance of this study.

\section{Appendix A. Supplementary data}

Supplementary data to this article can be found online at https://doi. org/10.1016/j.jep.2021.114282.

\section{Associated content}

Details pertaining to plant collection, identification, DNA barcoding, sample preparation as well as experimental methodologies, and spectral data can be found in the Supplementary Information document.

\section{Author contributions}

The manuscript was written through contributions of all authors. All authors have given approval to the final version of the manuscript. Talent Chipiti collected the plant material, performed the extractions, fractionation and isolation of the compounds in the laboratory of Alvaro M. Viljoen under his guidance and that of Gill M. Enslin, Talent Chipiti conducted the in vivo studies toxicity and bioactivity studies under the guidance of Maria Cordero-Maldonado and Alexander D Crawford, Clinton G. Veale and Fanie R. van Heerden conducted the NMR analysis and interpretation of spectra for identification of isolated compounds, Weiyang Chen and Maxlene Sandasi conducted the chromatographic analysis and assisted with interpretation of chromatographic data. Gill M Enslin coordinated the study and the compilation of the manuscript. Alvaro M Viljoen was responsible for the conceptualization of the project.

\section{References}

Afrikanova, T., Serruys, A.S.K., Buenafe, O.E.M., Clinckers, R., Smolders, I., De Witte, P. A.M., Crawford, Esguerra, C.V., 2013. Validation of the zebrafish pentylenetetrazol seizure model: locomotor versus electrographic responses to antiepileptic drugs. PloS One 8 (1), 1-9.

Auditeau, E., Chassagne, F., Bourdy, G., Bounlu, M., Jost, J., Luna, J., Ratsimbazafy, V., Preux, P.M., Boumediene, F., 2019. Herbal medicine for epilepsy seizures in asia, Africa and Latin America: a systematic review. J. Ethnopharmacol. 234, 119-153.

Bello, M.O., Jagaba, S.M., Bello, O.E., 2019. A wild edible vegetable Anchomanes difformis (Blume) Engl: its ethnomedicinal, phytochemistry, nutritional importance and other uses. EurAsia J. BioSci. 13, 1137-1147.

Berghmans, S., Hunt, J., Roach, A., Goldsmith, P., 2007. Zebrafish offer the potential for a primary screen to identify a wide variety of potential anticonvulsants. Epilepsy Res. 75 (1), 18-28.

Bienvenu, E., Amabeoku, G.J., Eagles, P.K., Scott, G., Springfield, E.P., 2002. Anticonvulsant activity of aqueous extract of Leonotis leonurus. Phytomedicine: International journal of phytotherapy and phytopharmacology 9 (3), 217-223.

Bosch, C.H., 2008. Bersama abyssinica fresen. In: Schmelzer, G.H., Gurib-Fakim, A. (Eds.), PROTA (Plant Resources of Tropical Africa/Ressources végétales de l'Afrique tropicale). Wageningen, Netherlands. (Accessed 18 May 2020).

Boukandou Mounanga, M., Mewono, L., Aboughe Angone, S., 2015. Toxicity studies of medicinal plants used in sub-Saharan Africa. J. Ethnopharmacol. 174, 618-627.

Brendler, T., Eloff, J.N., Gurib-Fakim, A., Phillips, L.D., 2010. African Herbal Pharmacopoeia, eighteenth ed. Association for African Medicinal Plants Standards, Baie du Tombeau, Mauritius. Graphic Press.

Burkill, H.M., 1985. The Useful Plants of West Tropical Africa, 1.

CBRA, 2010. Why are animals necessary in biomedical Research? www.ca.biomed.org.

Challal, S., Buenafe, O.E., Queiroz, E.F., Maljevic, S., Marcourt, L., Bock, M., Kloeti, W., Dayrit, F.M., Harvey, A.L., Lerche, H., Esguerra, C.V., de Witte, P.A., Wolfender, J.L., Crawford, A.D., 2014. Zebrafish bioassay-guided microfractionation identifies anticonvulsant steroid glycosides from the Philippine medicinal plant Solanum torvum. ACS Chem. Neurosci. 5, 993-1004.

Crawford, A.D., Esguerra, C.V., de Witte, P.A., 2008. Fishing for drugs from nature: zebrafish as a technology platform for natural product discovery. Planta Med. 74, $624-632$.

Cunliffe, V.T., 2016. Building a zebrafish toolkit for investigating the pathobiology of epilepsy and identifying new treatments for epileptic seizures. J. Neurosci. Methods 260, 91-95.

Cunliffe, V.T., Baines, R.A., Giachello, C.N.G., Lin, W.H., Morgan, A., Reuber, M., Russell, C., Walker, M.C., Williams, R.S.B., 2015. Epilepsy research methods update: understanding the causes of epileptic seizures and identifying new treatments using non-mammalian model organisms. Seizure 24, 44-51.

Ferreira- Machado, S.C., Rodrigues, M.P., Nunes, A.P., Dantas, F.J., De Mattos, J.C., Silva, C.R., Moura, E.G., Bezerra, R.J., Caldeira-de-Araujo, A., 2004. Genotoxic 
potentiality of aqueous extract prepared from Chrysobalanus icaco L. leaves. Toxicol. Lett. 151 (3), 481-487.

Fricke-Galindo, I., Jung-Cook, H., LLerena, A., López-López, M., 2018. Pharmacogenetics of adverse reactions to antiepileptic drugs. Neurol. English Ed. 33, 165-176.

Gad, S.C., 2014. Maximum tolerated dose. Encyclopedia of Toxicology 164.

Galstyan, D.S., Zabegalov, K.N., Tatyana, O., Amstislavskaya, T.G., Strekalova, T., Petersen, E.V., Kalueff, A.V., 2021. Unconventional anxiety pharmacology in zebrafish: drugs beyond traditional anxiogenic and anxiolytic spectra. J Pharm, BiochemBehavior 173205 .

Gao, Y., Zhou, D.S., Kong, L.M., Hai, P., Li, Y., Wang, F., Liu, J.K., 2012. Rauvotetraphyllines A-E, new indole alkaloids from Rauvolfia tetraphylla. Nat. Products Bioprospect. 2, 65-69.

Hacke, A.C.M., Miyoshi, E., Marques, J.A., Pereira, R.P., 2021. Cymbopogon citratus (DC.) Stapf, citral and geraniol exhibit anticonvulsant and neuroprotective effects in pentylenetetrazole-induced seizures in zebrafish. J. Ethnopharmacol. 275, 114142.

Hollingsworth, P.M., Forrest, L.L., Spouge, J.L., Hajibabaei, M., Ratnasingham, S., van der Bank, M., Chase, M.W., Cowan, R.S., Erickson, D.L., Fazekas, A.J., Graham, S.W., James, K.E., Kim, K., Kress, W.J., Schneider, H., van AlphenStahl, J., Barrett, S.C.H., van de Berg, C., Bogarin, D., Burgess, K.S., Cameron, K.L., Carine, M., Chacon, J., Clark, A., Clackson, J.J., Conrad, F., Devey, D.S., Ford, C.S., Hedderson, T.A.J., Hollingsworth, M.L., Husband, B.C., Kelly, L.J., Kesanakurti, P.R., Kim, J.S., Kim, Y., Lahaye, R., Lee, H., Long, D.G., Madrinan, S., Maurin, O., Meusnier, I., Park, N.C., Percy, D.M., Petersen, G., Salazar, R.G.A., Savolainen, V., Seberg, O., Wilkinson, M. J., Yi, D., Little, D.P., 2009. A DNA barcode for land plants. Proc. Natl. Acad. Sci. U. S. A 106 (31), 12794-12797.

Kayani, M.J., 1977. Rauvolfia caffra. Planta Med. 32 (3), 258-267.

Kinsou, 1., Adovelande, J., Assogba, M.F., Sezan, A., Gbenou, J.D., 2019. Evaluation of anti-convulsant activity of Afzelia africana leaves aqueous extracts on wistar rats. Res. J. Pharmaceut. Biol. Chem. Sci. 5 (1), 688.

Kowski, A.B., Weissinger, F., Gaus, V., Fidzinski, P., Losch, F., Holtkamp, M., 2016. Specific adverse effects of antiepileptic drugs - a true-to-life monotherapy study. Epilepsy Behav. 54, 150-157.

Kress, W.J., Erickson, D.L., Jones, F.A., Swenson, N.G., Perez, R., Sanjur, O., Bermingham, E., 2009. Plant DNA barcodes and a community phylogeny of a tropical forest dynamic plot in Panama. Proceedings of the National Academy of Science USA 106, 621-18626.

Kulkarni, S.K., Sharma, A., Verma, A., Ticku, M.K., 1993. GABA receptor mediated anticonvulsant action of Withania somnifera root extract. Journal of Indian Drugs 305-312.

Kulkarni, V., Dounde, S., Kureshi, T., Siddiqui, Areej, 2011. Evaluation of antiepileptic potential of Hibiscus sabdariffa Linn. Pharmacologyonline 3, 115-127.

Lamidi, M., Bourobou Bourobou, H., 2010. Mondia whitei (Hook.f.) skeels. In: Schmelzer, G.H., Gurib-Fakim, A. (Eds.), PROTA (Plant Resources of Tropical Africa) Ressources végétales de l'Afrique tropicale). Wageningen, Netherlands. (Accessed 5 March 2019).

Levin, R.A., Wagner, W.L., Hoch, P.C., Nepokroeff, M., Pires, J.C., Zimmer, E.A., Sytsma, K.J., 2003. Family-level relationships of Onagraceae based on chloroplast $r b c L$ and $n d h F$ data. Am. J. Bot. 90, 107-115.

MacRae, C.A., Peterson, R.T., 2015. Zebrafish as tools for drug discovery. Nat. Rev. Drug Discov. 14, 721-731.

Mathew, J., Paul, J., Nandhu, M.S., Paulose, C.S., 2010. Bacopa monnieri and Bacoside-A for ameliorating epilepsy associated behavioral deficits. Fitoterapia 81 (5), 315-322.
Mollel, N.P., 2007a. Rauvolfia caffra Sond. In: Schmelzer, G.H., Gurib-Fakim, A. (Eds.), PROTA (Plant Resources of Tropical Africa/Ressources végétales de l'Afrique tropicale). Wageningen, Netherlands. (Accessed 18 May 2018).

Mollel, N.P., 2007b. Rauvolfia caffra. In: Medicinal plants/Plantes Médicinales.

Mothogoane, M.S., 2013. Dioscorea Dregeana (Kunth) T.Durand \& Schinz. Plantzafrica. com. SANBI. Retrieved 18 June 2016.

Nasser, A.M.A.G., Court, W., 1984. Stem bark alkaloids of Rauvolfia caffra. J. Ethnopharmacol. 11, 99-117, 1984.

Okoye, T.C., Akah, P.A., Omeje, E.O., Okoye, F.B.C., Nworu, C.S., 2013. Anticonvulsant effect of kaurenoic acid isolated from the root bark of Annona senegalensis. Pharmacol., Biochem. Behav. 109, 38-43, 2013.

Olatokunboh, A.O., Kayode, Y.O., Adeola, O.K., 2009. Anticonvulsant activity of Rauvolfia vomitoria (afzel). African Journal of Pharmacy and Pharmacology 3 (6), 319-322.

Owoeye, O., Adedara, I.A., Adeyemo, O.A., Bakare, O.S., Egun, C., Farombi, E.O., 2015. Modulatory role of kolaviron in phenytoin-induced hepatic and testicular dysfunctions in Wistar rats. J. Diet. Suppl. 12 (1), 105-117.

Owolabi, L.F., Adamu, B., Jibo, A.M., Owolabi, S.D., Isa, A.I., Alhaji, I.D., Enwere, O.O., 2020. Prevalence of active epilepsy, lifetime epilepsy prevalence, and burden of epilepsy in sub-saharan Africa from meta-analysis of door-to-door population-based surveys. Epilepsy Behav. 103, 106846.

Schachter, S.C., 2009. Botanicals and herbs: a traditional approach to treating epilepsy. Neurotherapeutics : The Journal of the American Society for Experimental NeuroTherapeutics 6 (2), 415-420.

Schmidt, D., 2009. Drug treatment of epilepsy: options and limitations. Epilepsy Behav. $15,56-65$.

Singh, A., Trevick, S., 2016. The epidemiology of global epilepsy. Neurol. Clin. 34 (4), 837-847.

Tan, S.J., Lim, K.G., Kam, S.T., 2013. Macroline-sarpagine and macroline-pleiocarpamine bisindole alkaloids from Alstonia angustifolia. Phytochemistry 85.

Tan, S.J., Lim, J.L., Low, Y.Y., Sim, K.S., Lim, S.H., Kam, T.S., 2014. Oxidized derivatives of macroline, sarpagine, and pleiocarpamine alkaloids from Alstonia angustifolia. J. Nat. Prod. 77 (9), 2068-2080.

Tiraboschi, E., Martina, S., van der Ent, W., Grzyb, K., Gawel, K., Cordero-Maldonado, M. L., Poovathingal, S.K., Heintz, S., Somisetty Venkata Satheesh, S.V., Brattespe, J., Xu, J., Suster, M., Skupin, A., Camila, V., Esguerra1, K.A., 2020. New insights into the early mechanisms of epeileptogenesis in a zebrafish model of Dravet syndrome. Epilepsia 1-12, 00.

Umukoro, S., Ashorobi, R.B., 2005. Pharmacological evaluation of the central nervous system activity of Aframomum melegueta seed extract in mice. J. Nat. Remedies 5 (2), $141-146$.

Westerfield, M., 2000. The Zebrafish Book. A Guide for the laboratory use of Zebrafish (Danio rerio), 4th. University of Oregon Press, Eugene.

Wiley, D.S., Redfield, S.E., Zon, L.I., 2017. Chemical screening in zebrafish for novel biological and therapeutic discovery. Methods Cell Biol. 138, 651-679.

Zhang, B.J., Peng, L., Wu, Z.K., Bao, M.F., Liu, Y.P., Cheng, G.G., Luo, X.D., Cai, X., 2013. H. Indole alkaloids from leaves and twigs of Rauvolfia verticillata. J. Asian Nat. Prod. Res. 15, 1221-1229.

Zuberi, S.M., Symonds, J.D., 2015. Update on diagnosis and management of childhood epilepsies. J. Pediatr. 91 (6 Suppl. 1), S67-S77. 